\title{
El Género Mandevilla (Apocynaceae: Apocynoideae, Mesechiteae) en México
}

\author{
Leonardo O. Alvarado-CÁrdenas ${ }^{1,3}$ y J. Francisco Morales ${ }^{2}$ \\ 'Departamento de Botánica, Instituto de Biología, Universidad Nacional Autónoma de México, \\ México, D.F. México \\ ${ }^{2}$ Instituto Nacional de Biodiversidad (INBio), Santo Domingo, Heredia, Costa Rica \\ ${ }^{3}$ Autor para la correspondencia: leonardo_ac@yahoo.com
}

\begin{abstract}
Resumen: El género Mandevilla (Apocynaceae; Apocynoideae) es endémico del Neotrópico y uno de los géneros más diversos de la familia. En México, la última revisión de Mandevilla se realizó hace más de diez años; desde entonces nuevas especies fueron descritas, así como cambios en los límites del mismo. En este trabajo se presenta una revisión taxonómica actualizada para Mandevilla en México que incluye una clave para la identificación de especies, imágenes fotográficas, mapas de distribución e información acerca de la fenología. El total de especies de Mandevilla registradas para el país fue de 22. Oaxaca, Chiapas, Guerrero y Michoacán fueron las entidades con más especies. Las especies que se subordinaron a sinonimía fueron Mandevilla andrieuxii, M. karwinskii, M. pringlei y M. stans, mientras que se reconoció como distintas a M. apocynifolia, M. exilicaulis y M. oaxacensis.

Palabras clave: Apocynaceae, endemismo, Mandevilla, Oaxaca, revisión.
\end{abstract}

\begin{abstract}
Mandevilla (Apocynaceae; Apocynoideae) is an endemic Neotropical genus and one of the most diverse in the family. The Mexican Mandevilla were revised more than ten years ago, but since then new species have been described, and important changes have been made in its delimitation. An updated revision for Mandevilla in Mexico is presented, including a key to identify the species, morphological descriptions, photographic images, distributional maps, as well as information about habitat and flowering/fruiting times. Twenty-two species of Mandevilla are registered for the country. The states of Oaxaca, Chiapas, Guerrero, and Michoacán are the most species diverse. Mandevilla andrieuxii, M. karwinskii, M. pringlei are reduced to synonymy and M. stans, whreas $M$. apocynifolia, M. exilicaulis and $M$. oaxacensis are recognized as distintc.
\end{abstract}

Key Words: Apocynaceae, endemism, Mandevilla, Oaxaca, revision.

$\mathbf{E}_{\mathrm{p}}^{1}$ género Mandevilla Lindl. es endémico de América y pertenece a la tribu Mesechiteae de la subfamilia Apocynoideae (Endress y Bruyns, 2000; Simões et al., 2007). Es el género más diverso de la tribu y uno de los más numerosos de la familia con más de 170 especies (Morales, 1998, 2007a, b, 2009b; Simões et al., 2007). La sistemática de Mandevilla es controversial y se ha abordado por numerosos autores, quienes han sugerido cambios en los límites del género.

Entre los cambios más recientes se encuentra la subordinación de los géneros Quiotania Zarucchi, Macrosiphonia Müll. Arg. y Telosiphonia (Woodson) Henrickson (Simões et al., 2006, 2007). Tradicionalmente se planteó una relación cercana con estos géneros (Woodson, 1933; Henrickson, 1996; Morales, 1998), pero se mantenían como taxones distintos por el grado de diferenciación morfológica como respuesta a la adaptación en las zonas áridas donde se distribuyen (Henrickson, 1996). Sin embargo, Pichon (1948, 1950) consideró que las diferencias morfológicas no eran suficientes para reconocer a estos géneros como distintos de Mandevilla. No obstante, su propuesta no fue seguida durante decadas, por lo que estas entidades continuaron considerándose como géneros distintos en numerosos trabajos taxonómicos (Morales, 1998; Alvarado-Cárdenas, 2004a, b; Diego-Pérez, 2004).

Los primeros análisis filogenéticos para Apocynaceae no abordaron la problemática entre estos géneros (Endress et al., 1996; Sennblad y Bremer, 1996), ya que su objetivo estaba enfocado en resolver categorías superiores. Recientemente, los trabajos de Simões et al. $(2004,2006)$ para la tribu Mesechiteae y el género Mandevilla brindaron un importante paso en el entendimiento de las relaciones de estos 
taxones. Los resultados de estos análisis filogenéticos, basados en evidencia molecular y morfológica, corroboraron la cercanía de Quiotania, Macrosiphonia y Telosiphonia, y sugieren que estos tres se encuentran anidados dentro de Mandevilla (Simões et al., 2006). Posteriormente, Simões et al. (2007) subordinan y proporcionan los cambios nomenclaturales para las especies de Quiotania, Telosiphonia y Macrosiphonia.

Los trabajos taxonómicos realizados para Mandevilla en México son escasos, entre los que destacan los esfuerzos monográficos de Woodson (1932) y el tratamiento florístico para la familia Apocynaceae s.s. para Norte América (Woodson, 1938). Más tarde, Henrickson (1996) elevó al subgénero Telosiphonia perteneciente a Macrosiphonia a nivel de género y describe una especie y una variedad nuevas para México. Morales (1998) realizó una sinopsis de las especies de Mandevilla para México y Centroamérica, en la cual reconoce 15 especies para el país. Posteriormente, Williams (1998a, b, 2003, 2004) propuso una serie de cambios nomenclaturales para algunas especies de Mandevilla y describe una especie nueva para la flora mexicana; Simões $e t$ al. (2007) realizan los cambios nomenclaturales de las especies de Telosiphonia y Macrosiphonia, ahora subordinadas a Mandevilla. En ese mismo año, Juárez-Jaimes et al. (2007) proporcionan una lista de las especies de la familia Apocynaceae presentes en México donde se reconocen 21 especies para Mandevilla, pero no se aborda ninguna problemática, ni sinonimías asociadas a los taxones de este género. Por último, Morales (2009b) proporciona un tratamiento taxonómico de Mandevilla para Mesoamérica, donde reporta siete especies para la región mexicana y, Lozada-Pérez y DiegoPérez (2012) publican una nueva especie para el estado de Guerrero.

Actualmente, no hay una revisión que incluya todas las especies reconocidas para México, así como los cambios nomenclaturales recientes y la problemática sobre la delimitación de algunas especies. Con base en la información generada desde la última evaluación de Mandevilla para México, el objetivo del trabajo es presentar una revisión taxonómica de las especies del género en el país.

\section{Material y método}

La información que aquí proporcionamos proviene de una exhaustiva consulta bibliográfica de trabajos sistemáticos relacionados con el género (Woodson, 1932, 1933, 1938; Henrickson, 1996; Williams, 1996, 1998a, b, 1999, 2003, 2004; Allorge-Boiteau, 1998; Morales, 1998, 2005, 2007a, b, 2009a, b; Rzedowski y Calderón de Rzedowski, 1998; Calderón de Rzedowski y Rzedowski, 2001; AlvaradoCárdenas, 2004a, b; Diego-Pérez, 2004; Morales y Fuentes, 2004; Simões et al., 2004, 2007; Lozada-Pérez y Diego-Pérez, 2012). Esta información ha sido complementada con la revisión de ejemplares depositados en los siguientes herbarios: B, BM, C, ENCB, F, FCME, G, GH, IEB, INB, INEGI, K, MA, MEXU, MICH, MO, NY, P, QMEX, S, SERO, US y XAL (Holmgren et al., 1990). Asimismo, el primer autor realizó una serie de viajes a diferentes áreas del país para recolectar especímenes de la mayoría de las especies, así como fotografiar y preservar flores y frutos para el estudio en el laboratorio. Todos los especímenes recolectados fueron depositados en MEXU. Finalmente se realizó una exploración en algunas bases de datos (Arizona: http://ag.arizona.edu/herbarium/; Harvard: ww.huh.harvard. edu; Nueva York: www.ny.org; www.mnh.si.edu; REMIB: http://www.conabio.gob.mx/remib/doctos/remib_esp.html), para complementar la información sobre las especies de Mandevilla presentes en México.

Para cada especie se brinda una lista de sinónimos. Las descripciones de las partes de la corola infundibuliforme (tubo y garganta) siguen a Woodson (1932), donde la parte por debajo de la inserción de los estambres corresponde al tubo y la parte superior y ensanchada corresponde a la garganta. La información de fenología, hábitat y distribución altitudinal se tomó de las etiquetas de cada espécimen examinado, y se complemento con la información recopilada en los diferentes viajes de campo realizados. Asimismo, la información de distribución se georreferenció para generar los mapas de distribución. Se revisaron más de 1,200 especímenes, pero solamente se citan aquellos representativos para cada taxón. Una lista completa de los ejemplares estudiados puede ser solicitada, así como una copia de esta información se encuentra bajo resguardo de la UNIBIO en el Instituto de Biología de la UNAM.

\section{Resultados}

Mandevilla Lindl., Bot. Reg. 26: pl. 7. 1840.

Exothostemon G.Don., Gen. Hist. 4: 70, 82. 1837. Laseguea A.DC., Prodr. 8: 481. 1844. Dipladenia A.DC., Prodr., 8: 481. 1844. Heterothrix Müll.Arg., Fl. Bras. 6: 133. 1860. Macrosiphonia Müll.Arg., Fl. Bras. 6: 137. 1860. Amblyanthera Müll.Arg., Fl. Bras. 6: 141. 1860. Eriadenia Miers, Apocyn. S. Amer. 117. 1878. Micradenia (A.DC.) Miers, Apocyn. S. Amer. 158. 1878. Homaladenia Miers, Apocyn. S. Amer. 163. 1878. Angadenia Miers, Apocyn. S. Amer. 173. 1878. Temnadenia Miers, Apocyn. S. Amer. 207. 1878. Quiotania Zarucchi, Novon 1: 33. 1991. Telosiphonia (Woodson) Henrickson, Aliso 14: 179. 1996.

Bejucos, arbustos o hierbas, con látex lechoso, rara vez acuoso, tallos teretes o subteretes, rara vez alados longitudinalmente. Hojas persistentes o deciduas, opuestas a verticiladas, coléteres subulados, nodales, axilares y en la haz de las hojas agrupados en la base de la vena media o a lo largo de la misma, rara vez sobre la venas secundarias o ausentes, margen entero, a veces revoluto y/o undulado, membranáceas a subcoriáceas. Inflorescencias en racimos, 

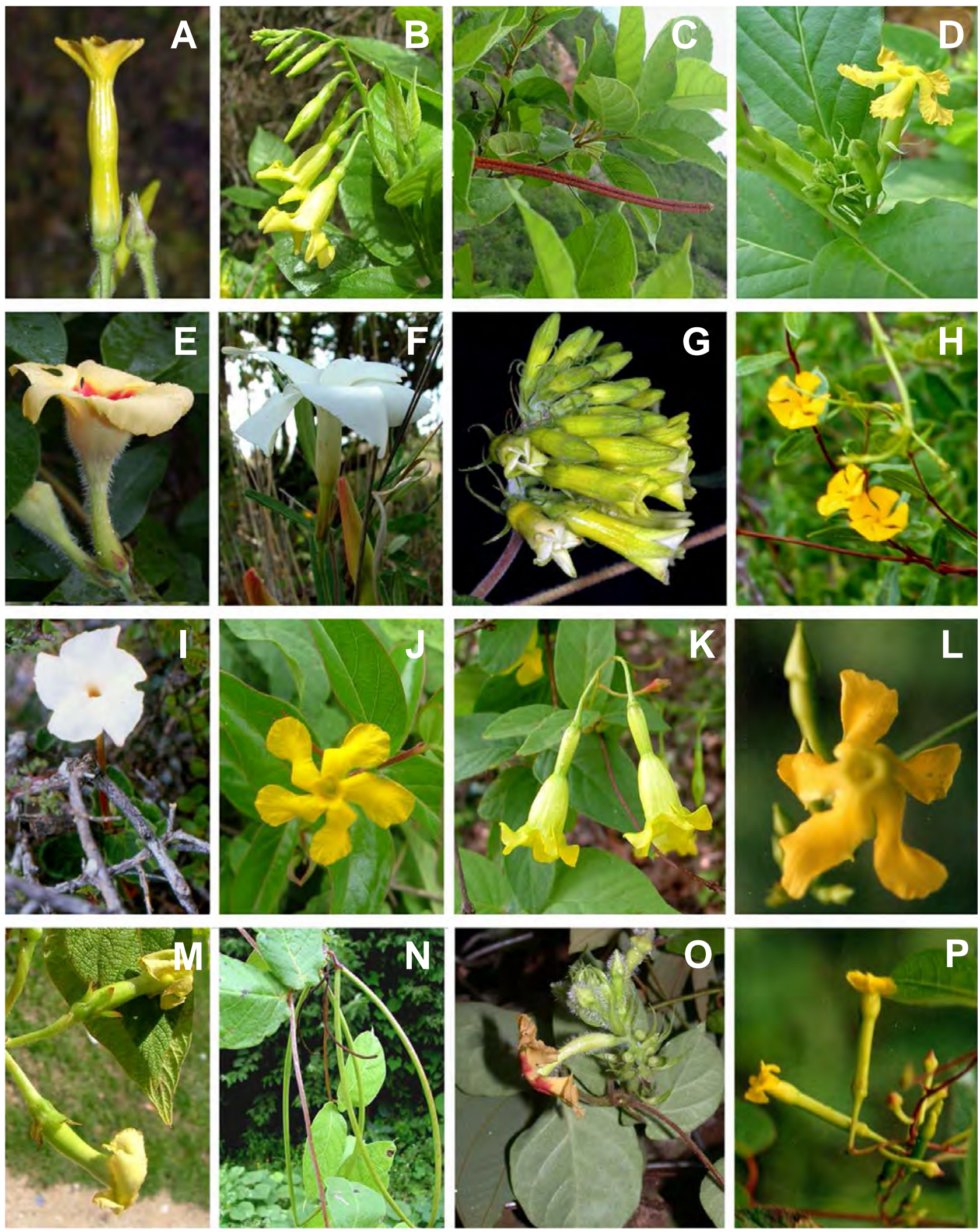

Figura 1. Algunas especies de Mandevilla presentes en México. A) M. acutiloba. B-C) M. convolvulacea. D) M. foliosa. E) M. hirsuta. F) M. hypoleuca. G) M. holosericea. H) M. torosa. I) M. lanuginosa. J) M. mexicana. K) M. oaxacana. L) M. subsagittata. M-N) M. subsessilis. O) M. villosa. P) M. tubiflora. Fotos: (G) V. Steinmann y Y. Ramírez; (A, E y O) F. Morales. 
axilares o terminales, flores numerosas o reducidas a 1-2 (-3). Flores hipóginas; sépalos con coléteres en la base de la cara adaxial; corola hipocraterimorfa, tubular o infundibuliforme, amarilla, blanca, rosada, roja o morada, lóbulos de prefloración dextrocontorta, extendidos, erguidos o reflexos; estambres 5, anteras sagitadas, subcordadas o subtruncadas, con las bases estériles, conectivo expandido, conniventes y aglutinadas a la cabeza estigmática, incluidas, dehiscencia introrsa; nectarios 2-5, libres, connatos en la base o totalmente fusionados y formando un disco; ovario apocárpico, los carpelos unidos en el ápice, óvulos numerosos, placentación marginal, estilo único, cabeza estigmática pentagonal umbraculiforme a gloquidada, con 5 crestas longitudinales. Frutos foliculares, libres o unidos en el ápice rara vez fusionados por completo, continuos a moniliformes, pubescentes a glabros; semillas lineares, comosas en el ápice micropilar.

Comentarios taxonómicos: Mandevilla es un género neotropical con alrededor de 170 especies, con la mayor diversidad en Sudamérica. México, con más de 20 especies, puede considerarse como un centro de diversificación, ya que presenta un mayor número de especies que otros países tropicales como Costa Rica (cinco especies), El Salvador (cuatro especies) y Guatemala (seis especies), así como un número importante de especies endémicas en la región de Mesoamérica y porciones del norte de México.

En México, el género Mandevilla está representado por 22 especies (Figuras. 1, 2, 3, 4). Este resultado es similar al número de especies obtenido por Juárez-Jaimes et al. (2007). No obstante, hay diferencias en la validación de especies. Por un lado, aquí se subordina a sinonimias $M$. andrieuxii, M. karwinskii, M. pringlei y M. stans, ésta última no incluida en el trabajo mencionado. Por otra parte, las especies que cambiaron de estatus taxonómico o que no fueron incluidas en el trabajo de Juárez-Jaimes et al. (2007) son Mandevilla apocynifolia, M. exilicaulis, M. oaxacensis y $M$. guerrensis, esta última recientemente descrita.

El género presenta una amplia distribución en el territorio nacional, encontrándose en 30 de las 32 entidades federativas, con excepción de Baja California y Tlaxcala (Figuras 3, 4). Las especies de más amplia distribución son Mandevilla foliosa, M. hypoleuca y M. subsagittata, que se encuentran en 18 o más estados. Los estados con mayor número de especies son Oaxaca con 13, Guerrero con nueve y, Chiapas y Michoacán con ocho cada uno. En cuanto al endemismo, hay 11 especies endémicas para México que representan el $50 \%$ del total para el género. Los estados con mayor número de especies endémicas son Oaxaca con cinco especies, seguido de Guerrero, Jalisco, Michoacán y Puebla cada uno de ellos con cuatro especies.

La forma de vida está repartida de manera más o menos equitativa, con 11 especies arbustivas o herbáceas y 12 trepadoras o bejucos. Aquí se consideró que Mandevilla torosa se comporta como un arbusto o como bejuco, por lo que está incluido en ambas categorías. Las especies del género están presentes en casi todos los ambientes, pero principalmente en el matorral xerófilo y bosque tropical caducifolio.

\section{Clave para la identificación de las especies del género Mandevilla en México}

1. Arbustos o hierbas.

2. Inflorescencias reducidas a 1-2 (-3) flores; sépalos foliosos o petaloides; corola infundibuliforme, blanca.

3. Tubo de la corola de igual o menor longitud que la garganta.

4. Láminas lineares a oblongo-elípticas, margen revoluto, no ondulado; subcoriáceas, pedúnculo (0.5-) 1-

$2.5(-6.5) \mathrm{cm}$.

M. hypoleuca

4. Láminas ovado-lanceoladas a oblongo-ovadas, margen no revoluto, ligeramente ondulado, membranáceas; pedúnculos ausentes o ca. $0.1 \mathrm{~cm}$.......... brachysiphon 3 . Tubo de la corola de mucho mayor longitud que la garganta.

5. Láminas orbiculares o reniformes. Endémica de Baja California Sur...................................... hesperia 5. Láminas ovadas, elípticas u oblongas. Presente en otros estados de México.

6. Sépalos generalmente mayores a $1.6 \mathrm{~cm}$, foliosos, verdes M. macrosiphon

6. Sépalos generalmente menores a $1.5 \mathrm{~cm}$, petaloides, rojizos.

7. Tubo de la corola mayor a $5 \mathrm{~cm}$ largo.

M. lanuginosa

7. Tubo de la corola menor a $5 \mathrm{~cm}$ largo.

8. Sépalos de (0.7-) 0.9-1.5 cm largo; corola con garganta 1.8-2.5 cm largo. Crece por arriba de los 1,500 m s.n.m. Endémica del centro y sur de México...

M. oaxacensis

8. Sépalos 0.5-0.9 cm largo; corola con garganta $1.1-1.7 \mathrm{~cm}$ largo. Crece por abajo de $\operatorname{los} 500 \mathrm{~m}$ s.n.m Endémica de la costa oeste de Sonora

.M. nacapulensis

2. Inflorescencias con más de 3 flores; sépalos escariosos a foliosos; corola hipocraterimorfa, amarilla.

9. Hojas con margen ligeramente revoluto, subcoriáceas. Tubo de la corola generalmente menor de $1 \mathrm{~cm}$ M. torosa

9. Hojas sin margen revoluto, membranáceas. Tubo de la corola generalmente mayor de $1 \mathrm{~cm}$.

10. Pedúnculos mayores de $3 \mathrm{~cm}$...M. apocynifolia 10. Pedúnculos menores de $2.5 \mathrm{~cm}$.

11. Pecíolos 0.5-1.3 cm largo; láminas $5-13.5 \mathrm{~cm}$ largo. Corola con tubo 1-1.5 cm; lóbulos 0.6$1 \mathrm{~cm}$ de largo, distribuida desde Chihuahua a Guerrero .................................................. foliosa 11. Pecíolos 0.2-0.6 cm largo; láminas 2-6.6 cm largo. Corola con tubo 0.9-1.3 cm; lóbulos 0.9$1.8 \mathrm{~cm}$ de largo, distribuida sólo en Oaxaca ........ M. mexicana 
1. Bejucos.

12. Láminas con coléteres en la base de la vena media, rara vez ausentes.

13. Corola infundibuliforme.

14. Corola con tubo de 9-14 mm de largo y garganta de 1-1.4 cm de largo, tubular

M. oaxacana

14. Corola con tubo menor a $6 \mathrm{~mm}$ de largo y garganta de $1 \mathrm{~cm}$ o menos de largo, campanulada.

15. Corola glabra a esparcidamente pubescente; garganta 5-8.5 mm de largo; lóbulos 5-6.5 × 4-7 mm. Endémica de los estados de Oaxaca y Puebla M. convolvulacea 15. Corola glabra; garganta $8-10 \mathrm{~mm}$ de largo; lóbulos 2-2.5 $\times 2 \mathrm{~mm}$. Endémica de los estados de Colima, Jalisco y Michoacán .....

M. exilicaulis

13. Corola hipocraterimorfa o tubular.

16. Estambres insertos por arriba de la mitad del largo del tubo

17. Brácteas 2-4 mm de largo; sépalos 2$3.5 \mathrm{~mm}$ largo, escariosos ......... . tubiflora 17. Brácteas (3-) 5-12 (-15) mm largo; sépalos 6-13 mm largo, foliosos

.M. subsessilis

16. Estambres insertos en la parte media del tubo.

18. Tubo de la corola $1.4-2 \mathrm{~cm}$ largo ....... M. acutiloba

18. Tubo de la corola $0.5-1.3 \mathrm{~cm}$ largo.

19. Corola con lóbulos erectos

M. holosericea

19. Corola con lóbulos extendidos.

20. Hojas elípticas a estrechamente elípticas, membranáceas; corola con lóbulos 3.5-4 mm de largo

M. guerrerensis

20. Hojas elípticas a lanceoladas u oblongas a espatuladas, subcoriácea; corola con lóbulos 4-8 mm de largo .... M. torosa

12. Láminas con coléteres a lo largo de la vena media.

21. Corola infundibuliforme

M. hirsuta

21. Corola hipocraterimorfa.

22. Brácteas 1.2-2.9 (-3.5) $\mathrm{cm}$ largo, foliosas; sépalos 1-2 mm largo ......... M. villosa

22. Brácteas 0.2-0.5 cm largo, escariosas; sépalos 1.5-3.5 mm largo .......

M. subsagittata
1. Mandevilla acutiloba (A.DC.) Woodson, 19(1): 54. 1932. Echites acutilobus A.DC. Prodr. 8: 451. 1844. Amblyanthera acutiloba (A.DC.) Müll.Arg., Linnaea 30: 426. 1860. Tipo. México. Michoacán: habitat in frigidis Chucandiri montibus, s.f. (fl), M. Sessé y J. M. Mociño s.n. (Holotipo: G-DC!, foto F negativo 34138!).

Echites rosanus Donn.Sm., Bot. Gaz. 40: 6. 1905. Mandevilla rosana (Donn.Sm.) Woodson, Ann. Missouri Bot. Gard. 19: 56. 1932. Tipo. Guatemala. Santa Rosa: Buena Vista, 04/1893 (fl.), E. T. Heyde y E. Lux 4540, (Holotipo: US!; Isotipos: B (destruido), GH!, K!)

Echites torulosus Sessé \& Moc., F1. Mexic. 45. 1887, non Echites torulosus L. Sp. P1. ed. 2. 307. 1762. Tipo. México. Michoacán: habitat in frigidis Chucandiri montibus, s.f. (fl.), M. Sessé y J. M. Mociño 1426 (Lectotipo, designado por Morales (1998): MA!, foto F neg 41252!; Isolectotipo: MA).

Mandevilla scorpioidea Woodson, Ann. Missouri Bot. Gard. 19: 56-57. 1932. Tipo. México. Chiapas: Cerro de Boquerón, 06/1914 (fl.), C. A. Purpus 7274 (Holotipo: MO!; Isotipos: BM!, F!, GH!, NY!, US!).

Mandevilla contrerasii Lundell, Wrightia 5: 257-258. 1976. Tipo. Guatemala. Baja Verapaz: Unión Barrios, 16/06/1975 (fl.), G. L. Lundell y E. Contreras 19461 (Holotipo: LL; Isotipos: F!, foto F neg 61420!, MO!, S!, foto INB!).

Bejucos, tallos densa a escasamente hispídulos. Hojas con pecíolo 0.7-1.5 cm largo; láminas (2-) 4.5-14.2 (1.7) $\times 2.6-5.6 \mathrm{~cm}$, elípticas, ovadas a estrechamente ovadas, base cordada, ápice acuminado, márgenes a veces revolutos, membranáceas, haz escaso puberulento a glabrescente, con coléteres en la base de la vena media, envés tomentoso a tomentuloso, raramente glabro. Inflorescencias con 5-11flores; pedúnculo 3-6.5 cm largo; brácteas 3.5-8 mm largo, ovado-lanceoladas a linear-lanceoladas, escariosas, pubescentes; pedicelo 0.6-1.5 cm largo; sépalos 4-7 mm largo, ovado-lanceolados, escariosos, pubescentes; corola hipocraterimorfa, amarilla verdosa a amarillenta, glabra, tubo 1.4- $2 \mathrm{~cm} \times$ ca. $2 \mathrm{~mm}$, recto; lóbulos 4-6 $\times 2-3 \mathrm{~mm}$, estrechamente obovados a obovados, extendidos; estambres insertos en la parte media del tubo, anteras ca. $4 \mathrm{~mm}$ largo. Folículos $22-25 \times 0.3 \mathrm{~cm}$, libres, continuos, glabros, sin lenticelas; semillas 8-9 mm largo. Figura 1A.

Distribución y ecología: En México (Chiapas, Guerrero, Michoacán y Oaxaca; Figura 3A), El Salvador, Guatemala y Honduras. Crece en bosque tropical caducifolio en elevaciones de 1,000 a 2,100 m s.n.m. La floración y fructificación ocurren en febrero y de junio a septiembre.

Comentarios taxonómicos. Mandevilla acutiloba (Figura 1A) es comúnmente confundida con M. tubiflora (Figura 1P), pero difiere de esta última por los estambres insertos en la mitad del tubo y botones florales con el ápice agudo. La forma de los botones florales es un carácter que puede ser muy útil para separar taxones cercanamente relacionados (Morales, 1998, 2009a), como también puede verse en $M$. convolvulacea y M. exilicaulis. 


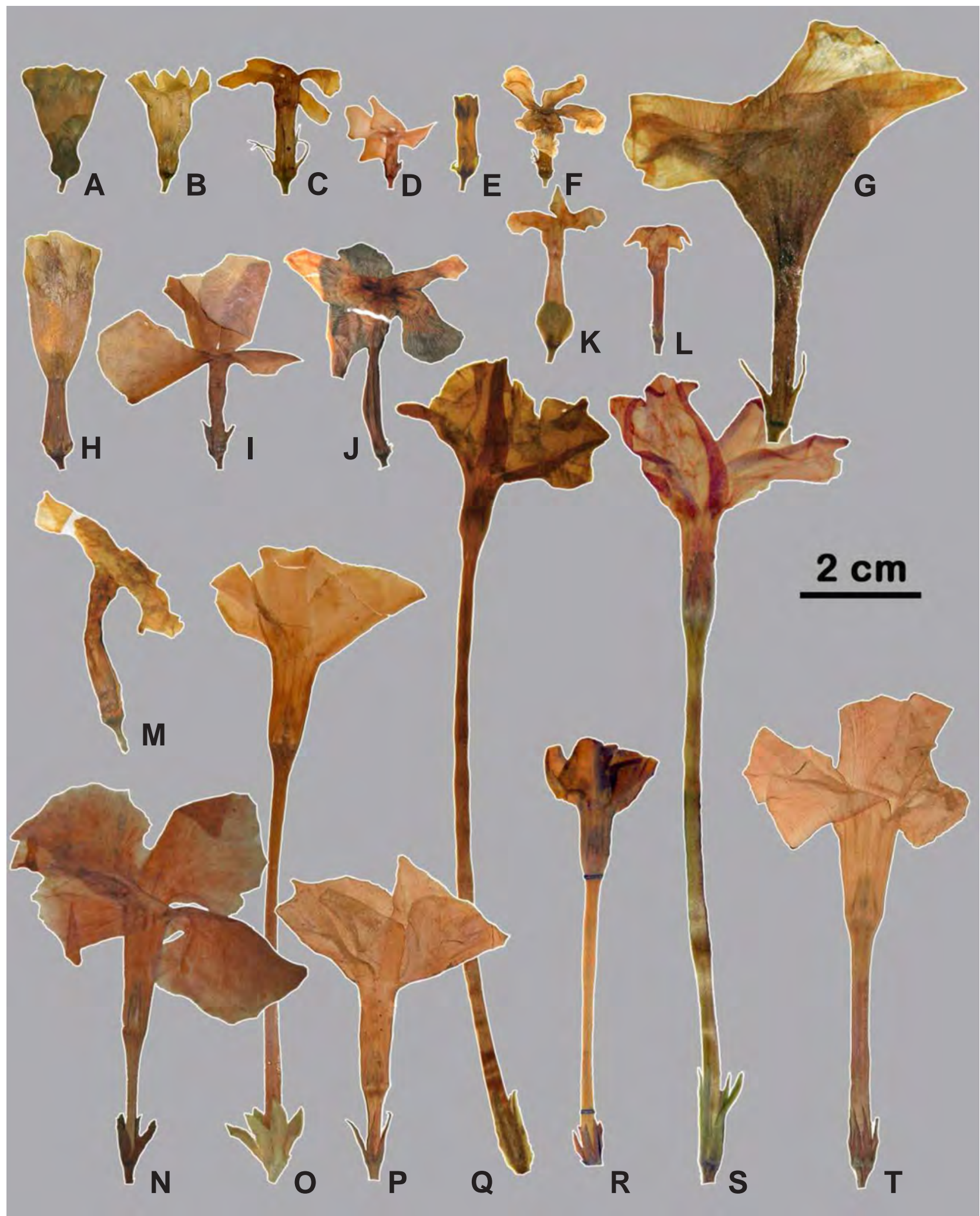

Figura 2. Relación de tamaño y forma de las flores en las especies de Mandevilla presentes en México. A) M. exilicaulis. B) M. convolvulacea. C) M. foliosa. D) M. torosa. E) M. holosericea. F) M. mexicana. G) M. hirsuta. H) M. oaxacana. I) M. apocynifolia. J) M. subsagittata. K) M. subsessilis. L) M. tubiflora. M) M. villosa. N) M. hypoleuca. O) M. hesperia. P) M. brachysiphon. Q) M. lanuginosa. R) M. nacapulensis. S) M. macrosiphon. T) M. oaxacensis. 
Para esta especie se consideraba que el colector del holotipo era J. Pavón (De Candolle, 1844; Morales, 1998). Sin embargo, J. Pavón y H. Ruiz nunca colectaron en México y la colecta corresponde a M. Sessé y M. Mociño. Este problema de confusión en los colectores se atribuye a De Candolle, quien recibió de Pavón duplicados de las colectas de Sessé y Mociño (Williams, 1999). De Candolle confundió y atribuyó las colectas de ésta y otras especies (Echites secundiflorus = Mandevilla subsagittata, Haplophyton cimicidum, Echites convolvulaceus = M. convolvulacea y Echites subsessilis $=$ M. subsessilis) a Pavón (Nelson, 1997; Williams, 1999). En este trabajo se ha corregido esta confusión de colectores para las especies de Mandevilla reportadas para el país.

Ejemplares seleccionados: Chiapas. Cerro del Boquerón, Purpus 7274 (MO). Guerrero. Mpio. Atixtlac de Tejapa, E of Petatlán on road to Teapa, Anderson et al. 5751 (ENCB, MICH). Michoacán. Chucandiri montibus, Sessé y Mociño 1426 (MA). Oaxaca. Mpio. Santa María Ecatepec, al E de San Lorenzo, la entrada se encuentra a $16 \mathrm{~km}$ al W de la Reforma, Martínez 1500 (MEXU).

2. Mandevilla apocynifolia (A.Gray) Woodson, Ann. Missouri Bot. Gard. 19(1): 65. 1932. Echites apocynifolius A.Gray, Proc. Amer. Acad. Arts 22: 435. 1887. Tipo. México. Jalisco: Río Blanco, 07/1886 (fl.), E. Palmer 734 (Holotipo: GH! Los duplicados depositados en K! y NY! corresponden a M. foliosa).

Mandevilla pringlei J.K.Williams, Sida 18(1): 231-235, f. 1, 2B, 3B. 1998. Tipo. México. Jalisco: Río Blanco, near Guadalajara, 22/07/1902 (fl.), C. G. Pringle 11357 (Holotipo: US!; Isotipo: G!).

Arbustos o hierbas $0.4-1.5 \mathrm{~m}$ alto, tallos puberulentos. Hojas con pecíolo 1-5 mm largo; láminas 3-9.5 × 1.5-3.8 cm, ovadas, elípticas a oblongo-lanceoladas, base subcordada, ápice agudo a acuminado, márgenes rectos, membranáceas, haz pubérulo, con coléteres en la base de la vena media, envés pubescente sobre la venación. Inflorescencias con 3-10 flores; pedúnculo (3-) 3.5-10 cm largo; brácteas 4-7 mm largo, lanceoladas, escariosas a foliosas, pubescentes; pedicelo 1-2.3 cm largo; sépalos 4-7 mm largo, angostamente ovadolanceolados, foliosos, pubescentes; corola hipocraterimorfa, amarilla, glabra, tubo de $1.5-1.8 \times 0.2-0.3 \mathrm{~cm}$, recto, lóbulos 1.4-1.9 × 1.5-1.7 cm, obovados, extendidos; estambres insertos arriba de la mitad del tubo, anteras ca. $3 \mathrm{~mm}$ largo. Folículos de 6-9 × 0.4-0.5 cm, libres, submoniliformes, sin lenticelas; semillas 7-8 mm largo. Figura 2I.

Distribución y ecología: Endémica de México (Jalisco, Michoacán y Nayarit; Figura 3B). Crece en bosque tropical caducifolio y zonas perturbadas a elevaciones de 1,7001,950 m s.n.m. La floración y fructificación ocurre de junio a agosto.

Comentarios taxonómicos. Echites apocynifolius fue descrita por Asa Gray (Watson, 1887) basado en el ejem-

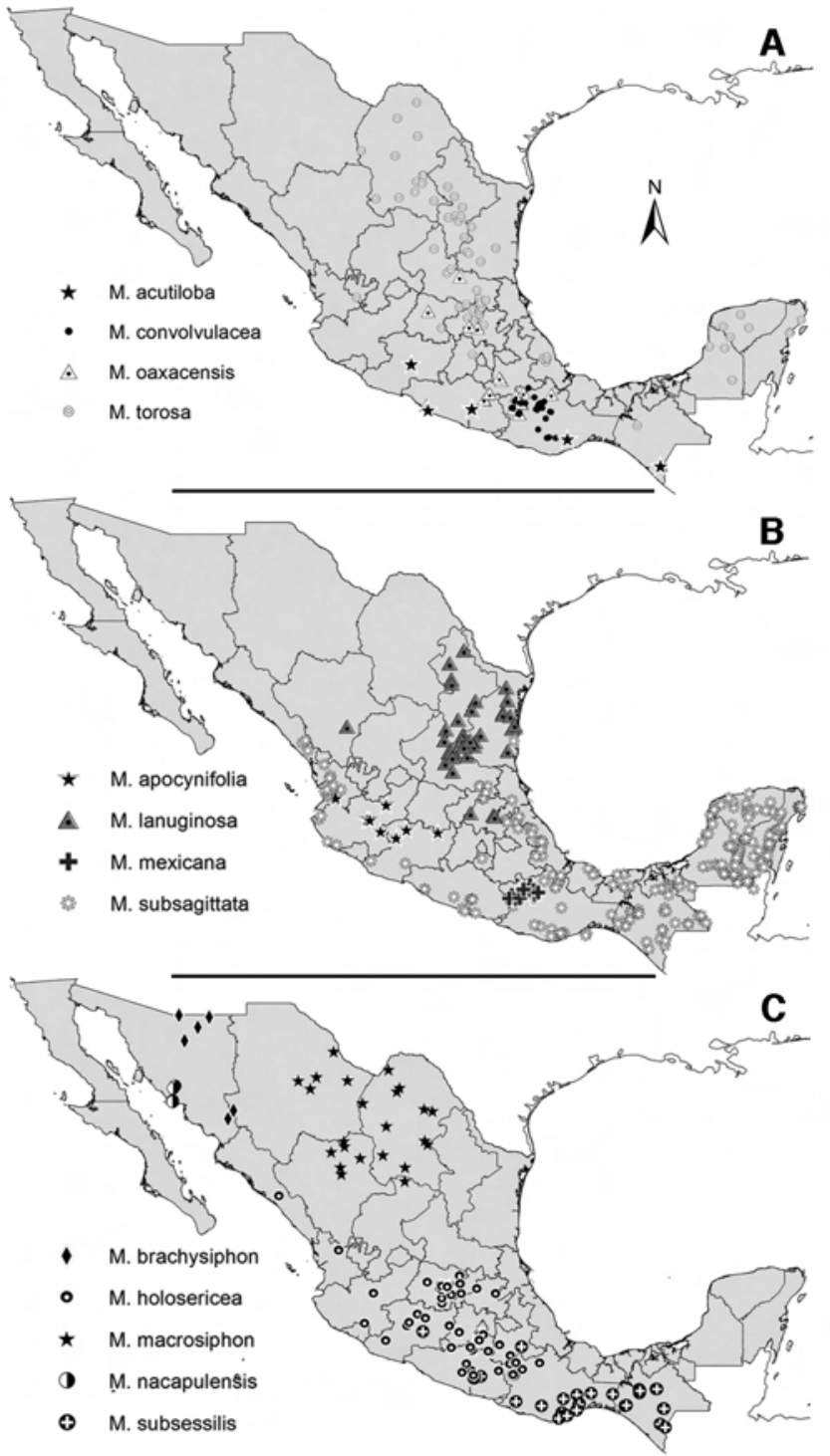

Figura 3. Mapa de distribución de las especies Mandevilla en México. A) M. acutiloba, M. convolvulacea, $M$. oaxacensis y $M$. torosa. B) Mandevilla apocynifolia, M. lanuginosa, M. mexicana y M. subsagittata. C) Mandevilla brachysiphon, M. holosericea, M. macrosiphon, M. nacapulensis y M. subsessilis.

plar de E. Palmer 734, que fué recolectado en la localidad de Río Blanco, Jalisco. Posteriormente, Woodson (1932) transfirió la especie al género Mandevilla (M. apocynifolia). No obstante, las colectas de E. Palmer bajo el número 734 son una mezcla de especímenes de diferentes especies. Por un lado, el holotipo depositado en el GH corresponde a la descripción de M. apocynifolia, con hojas corto pecioladas, largos pedúnculos y flores más grandes que las de M. folio$s a$. Por otra parte, los duplicados repartidos a los herbarios $\mathrm{K}$ y NY tienen hojas con pecíolos más grandes y frutos con pedúnculos cortos, que corresponden claramente a $M$. foliosa. Esta confusión pudó resultar porque M. apocynifolia 


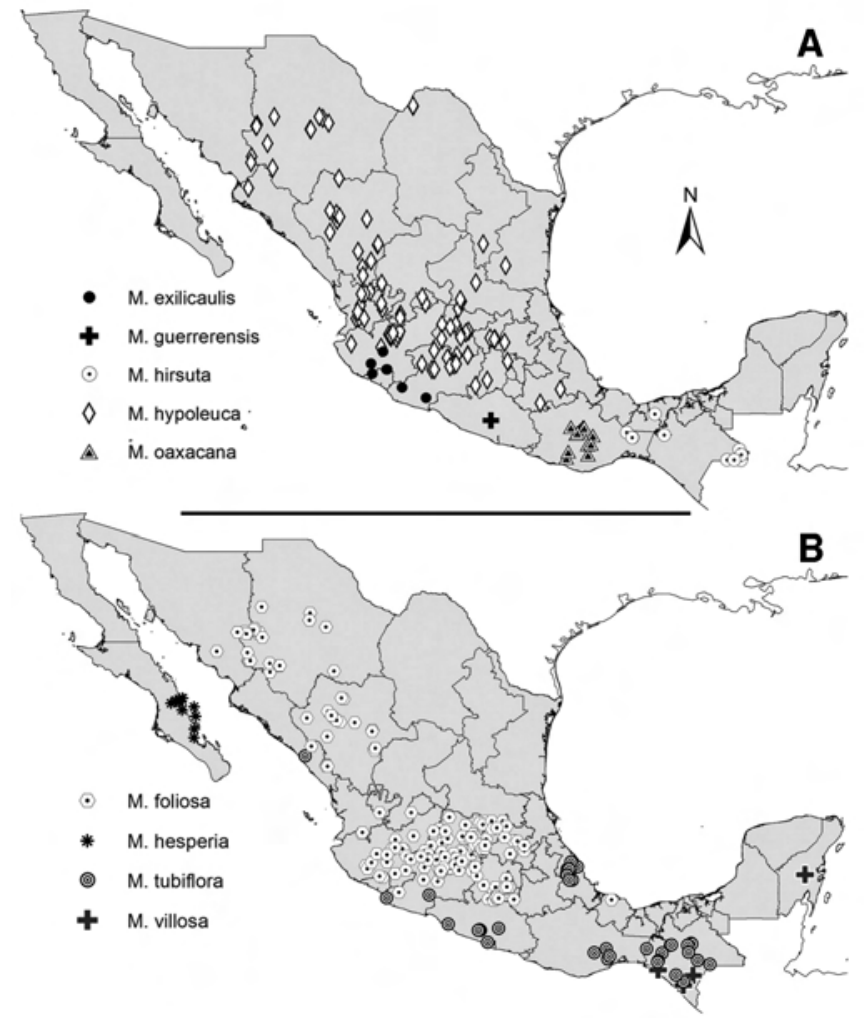

Figura 4. Mapa de distribución de las especies Mandevilla en México. A) M. exilicaulis, M. guerrerensis, M. hirsuta, M. hypoleuca y M. oaxacana. B) M. foliosa, M. hesperia, M. tubiflora y M. villosa.

es simpátrica con M. foliosa (Figura 3), por lo que es muy probable que por una equivocación de Palmer, debida a la similitud entre ambas especies (Figura 2C, I), haya mezclado ambos taxones en el mismo número de colecta.

En la localidad antes mencionada, también fue recolectado el tipo de Mandevilla pringlei por C. G. Pringle bajo el número 11357, y descrita por Williams (1998a) en honor al colector. Cuando Williams describió a M. pringlei, subordina a $M$. apocynifolia como sinónimo de $M$. foliosa, basado en que sus atributos corresponden más a esta última especie. No obstante, Williams (1998a) basó su resolución en la observación del isotipo depositado en NY, el cual cuenta con las características de M. foliosa. Williams al no tener acceso al holotipo, que le permitiera corroborar los atributos florales de la especie y del protólogo, pasó por alto el error de determinación de los especímenes arrastrado desde la publicación de M. apocynifolia. En este trabajo se revalida a $M$. apocynifolia como un taxón legítimo, basado en la observación del holotipo en $\mathrm{GH}$, y se subordina a M. pringlei como su sinónimo.

Ejemplares seleccionados: Jalisco. Mpio. Zapotitlán, Cerro Viejo, S face, above Zapotitan de Hidalgo, a village about $1 \mathrm{mi}$. N of highway Mex 15, Gregory et al. 223
(MEXU, MO); Mpio. Arandas, camino a microondas Cerro Gordo, Ramírez 2823 (MEXU). Michoacán. Mpio. Los Reyes, Atapam, Labat s.n. (MEXU); Mpio. Tlazazalca, camino al Cerro de la Cruz, Pérez 1358 (MEXU, ENCB, IEB). Nayarit. Mpio. San Pedro Lagunillas, $5 \mathrm{~km}$ al $\mathrm{S}$ del poblado de San Pedro Lagunillas, en las faldas del Cerro Grande de San Pedro, Calzada 18768 (MEXU).

3. Mandevilla brachysiphon (Torr.) Pichon, Bull. Mus. Natl. Hist. Nat., sér. 2, 20: 106. 1948. Echites brachysiphon Torr., Rep. U.S. Mex. Bound., Bot. 2 (1): 158. 1859. Macrosiphonia brachysiphon (Torr.) A.Gray, Syn. Fl. N. Amer. 2(1): 83-84. 1878. Telosiphonia brachysiphon (Torr.) Henrickson, Aliso 14(3): 187. 1995 [1996]. Tipo. México. Sonora: Gravelly hillside, San Bernardino, 08/1852 (fl.), $G$. Thurber 764 (Lectotipo: NY!, designado por Henrickson (1996); Isolectotipos: GH!, NY!).

Macrosiphonia dulcis A.Nelson, Amer. J. Bot. 21: 577. 1934. Tipo. Estados Unidos. Arizona. Lower mt. slopes of Huachuca Mts, 22/08/1907 (fl.), L. N. Goodding 2413 (Holotipo: RM!; Isotipo: NY!).

Macrosiphonia brachysiphonia (Torr.) A.Gray var. magnifica Woodson, Ann. Missouri Bot. Gard. 26(2): 97. 1939. Tipo. México. Sonora: fila al S de Arroyo Gochico, al E de San Bernardo, 5-9/08/1935 (fl.), F. W. Pennell 19524 (Holotipo: US!; Isotipo: MEXU!).

Macrosiphonia woodsoniana Standl., Publ. Field Mus. Nat. Hist., Bot. Ser. 22(1): 43. 1940. Tipo. México. Chihuahua: Río Mayo, Guasaremos, 30/07/1936 (fl.), H. S. Gentry 2342 (Holotipo: F!; Isotipos: A!, ARIZ-2, K!, MEXU!, MO!, S!, US!).

Arbustos $20-40 \mathrm{~cm}$ alto, rizomatosos, tallos tomentulosos a glabrescentes. Hojas con pecíolo 1-2 mm largo, láminas 1$2.9 \times 0.6-1.5 \mathrm{~cm}$, ovado-lanceoladas a oblongo-ovadas, base obtusa a subcordada, ápice agudo, márgenes ligeramente ondulados, membranáceas, haz piloso, con coléteres en la base de la vena media, envés esparcidamente tomentuloso. Inflorescencias con 1 (-2) flores; pedúnculo ausente o ca. 1 mm largo; brácteas 3-5 mm largo, lanceoladas, escariosas, tomentulosas; pedícelo $0.5-1.5 \mathrm{~cm}$ largo; sépalos $5-8 \mathrm{~mm}$ largo, ovado-lanceolados, foliosos; corola infundibuliforme, blanca, con tonos rosados, pubescente, tubo 1.8-2.5 $\times$ $0.2-0.3 \mathrm{~cm}$, recto, garganta $1.2-2.5 \times 0.5-0.7 \mathrm{~cm}$, tubular, lóbulos 1.5-2.7 × 1.2-2.5 cm, obovados, extendidos; estambres insertos en la base de la garganta, anteras 7-8 mm largo. Folículos 10-11 × 0.3-0.5 cm, libres, continuos, diminutamente pubescentes, sin lenticelas; semillas 5-7 $\mathrm{mm}$ largo. Figura 2P.

Distribución y ecología: En al sureste de EUA y México (Chihuahua y Sonora; Figura 3C). Esta especie crece en la vegetación de tipo matorral xerófilo a bosque espinoso entre los 1,000 a los 1,600 m s.n.m. La floración y fructificación ocurre entre junio y agosto.

Ejemplares seleccionados: Chihuahua. Mpio. Río Mayo, 
Guasaremos, Gentry 1839, 2342 (MO). Sonora. 10.3 miles east of Cucurpe, Goldberg 77-135 (MEXU); Mpio Nogales, $13.5 \mathrm{~km}$ East of Nogales on road to Santa Cruz, Van Devender 2001-556 (MEXU).

4. Mandevilla convolvulacea (A.DC.) Hemsl., Biol. Cent.Amer., Bot. 2(10): 316. 1882. Echites convolvulaceus A.DC., Prodr. 8: 451. 1844. Amblyanthera convolvulacea (A. DC.) Müll.Arg., Linnaea 30: 430. 1860. Tipo. México. Sin localidad, s.f. (fl.), M. Sessé y J. M. Mociño s.n. (Holotipo: G-DC!, foto F neg. 34140!)

Amblyanthera andrieuxii Müll.Arg., synon. nov. Linnaea 30: 422.1860. Echites andrieuxii (Müll.Arg.) Miers, Apocyn. S. Amer. 206. 1878. Mesechites andrieuxii (Müll. Arg.) Miers, Apocyn. S. Amer. 250. 1878. Mandevilla andrieuxii (Müll.Arg.) Hemsl., Biol. Cent.-Amer., Bot. 2: 316. 1882. Tipo. México. Oaxaca: San Francisco, entre Havapan [Huajuapan] y Oaxaca, s. f. (fl.), G. Andrieux 249 (Holotipo: G-DC!, foto F neg. 26874!; Isotipos: K-2!, P-2!).

Echites subcordatus Sessé \& Moc., Fl. Mexic. 44. 1887. Tipo. México. Oaxaca: habitat in Acahuitzotlae montibus, s. f. (fl.), M. Sessé y J. M. Mociño 1428 (Lectotipo, designado por Morales (1998): MA!).

Bejucos, tallos puberulentos a glabrescentes. Hojas con pecíolo (0.6-) 1.3-2.5 cm largo; láminas 2-10 (-12.2) × 1.4$6.8 \mathrm{~cm}$, ovadas, elípticas a obovadas, base cordada rara vez obtusa, ápice acuminado u obtuso y mucronado, márgenes rara vez revolutos, membranáceas, haz escaso puberulento a glabro, con coléteres en la base de la vena media, a veces un tanto extendidos, envés tomentuloso, rara vez glabro. Inflorescencias con 7-16 flores; pedúnculo 1.7-5 cm largo; brácteas 3-6 mm largo, ovado-lanceoladas, escariosas; pedicelo 0.6-1.3 cm largo; sépalos 2-3 mm largo, ovado-lanceolados a lanceolados, escariosos, pubescentes; corola infundibuliforme, amarilla a amarillo-verdosa, glabra a esparcidamente pubescente; tubo (3.5-) 4-5 × 3-3.5 mm, recto; garganta 58.5 × 5-8 mm, campanulada; lóbulos 5-6.5 × 4-7 mm obovados, extendidos; estambres insertos en la base de la garganta, anteras 3.5-4 mm largo. Folículos 12.5-16.5 × 0.2-0.3 $\mathrm{cm}$, generalmente unidos, continuos, glabros, con lenticelas; semillas 1.0-1.3 cm largo. Figuras 1B, C, 2B.

Distribución y ecología: Endémica de México (Oaxaca y Puebla; Figura 3A). Crece en bosque tropical caducifolio, bosque de pino y encino y en vegetación secundaria a una elevación de 1,400-2,000 m s.n.m. La floración ocurre entre mayo y julio y la fructificación de julio a septiembre.

Comentarios taxonómicos. La especie Mandevilla andrieuxii era considerada un taxón distinto y cercanamente relacionado con $M$. oaxacana, $M$. exilicaulis y $M$. convolvulacea, debido al hábito trepador y la corola infundibuliforme amarilla (Morales, 1998; Williams, 2004). La observación realizada al material tipo de $M$. andrieuxii, así como de las especies relacionadas, muestra que éste es un taxón distinto de M. oaxacana y M. exilicaulis, pero no de M. con- volvulacea, con la que comparte las mismas características morfológicas y el área de distribución. Ambas especies se distinguían con base en la longitud de los pecíolos, la forma de la hoja, la densidad de coléteres en la base de la lámina y la pubescencia de la corola (Woodson, 1933; Morales, 1998). La observación de los ejemplares tipo y de los especímenes de los herbarios reveló que dichas diferencias no son consistentes para reconocer a ambos taxones como distintos. Aquí se subordinó a $M$. andrieuxii como sinónimo de M. convolvulacea, que fue publicada por A. De Candolle en 1844 como Echites convolvulaceus, y tiene prioridad sobre Echites andrieuxii publicada en 1860 (Müller, 1860). Para esta especie se consideraba que el colector del holotipo era J. Pavón, se corrigió esta información y se agregó a Sessé y Mociño como colectores del holotipo.

Ejemplares seleccionados: Oaxaca: Mpio. Santiago Nacaltepec, $16 \mathrm{~km}$ SE de Santiago Dominguillo-Oaxaca, Chiang et al. F-1788 (MEXU); $15 \mathrm{~km} \mathrm{~S}$ de Dominguillo, sobre la carretera a Oaxaca, Rzedowski 34931 (ENCB, MEXU, MO); Mpio. Villa de Tamazulapam del Progreso, $15 \mathrm{~km}$ SW de Villa de Tamazulapam del Progreso, camino a Villa de Chilapa de Díaz, García-Mendoza et al. 2313 (MEXU); Chiconemchitl, Liebmann 11970 (C, F, US). Puebla: Mpio. San Gabriel Chilac, Cañada Tlacuilosto, SW de San Juan Atzingo, Alvarado et al. 154 (MEXU); Bartolo, Karwinski 269 (BR).

5. Mandevilla exilicaulis (Sessé \& Moc.) J.K.Williams, Lundellia 6: 144-147, f. 1-3. 2003. Echites exilicaulis Sessé \& Moc., F1. Mexic. 45. 1887. Tipo. México. Sin localidad, s. f. (fl.), M. Sessé y J. M. Mociño 5084 (Lectotipo: MA, foto INB!, designado por Morales, 1998).

Bejucos, tallos glabros. Hojas con pecíolo 2-8 mm largo; láminas 2-5 × 1-2 cm, elípticas a obovadas, base cordada, ápice agudo u obtuso y corto mucronado, márgenes rectos a rara vez revolutos, membranáceas, haz glabro a esparcidamente pubescente, con coléteres en la base de la vena media, envés esparcidamente pubescente. Inflorescencias 3-8-flores; pedúnculo 3.5-5.5 cm largo; brácteas $1.5-2 \mathrm{~mm}$ largo, escariosas, glabras; pedicelo 0.8-1.1 cm largo; sépalos 1-2 $\mathrm{mm}$ largo, ovados, escariosos, glabros; corola infundibuliforme, amarillo-verdosa, glabra; tubo 3-4 × 3-3.5 mm, recto, garganta 0.8-1 × 0.5-0.6 cm, campanulada; lóbulos 2-2.5 $\times 2 \mathrm{~mm}$, ovados, ligeramente reflexos; estambres insertos en la base de la garganta, anteras 2-2.5 mm largo. Folículos ca. $8 \times 0.3 \mathrm{~cm}$ (inmaduros), submoniliformes; semillas desconocidas. Figura 2A.

Distribución y ecología: Endémica de México (Colima, Jalisco y Michoacán; Figura 4A). Crece en bosque tropical caducifolio y bosque de pino-encino a elevaciones de $0-1,100$ m s.n.m. La floración ocurre entre noviembre y febrero.

Comentarios taxonómicos. Mandevilla exilicaulis (Figura 2A) puede confundirse con $M$. convolvulacea por su aspecto general (Figuras 1B, C, 2B). No obstante, M. exili- 
caulis presenta flores glabras (contra esparcidamente pubescentes), los botones florales presentan un ápice obtuso (contra acuminado), con lóbulos de 2-2.5 mm de largo (contra 5-6.5 mm), así como una distribución claramente disyunta que la hace fácilmente reconocible de este otro taxón.

Ejemplares seleccionados: Colima. Mpio. Manzanillo, $41 \mathrm{~km}$ al N de Manzanillo. $3.5 \mathrm{~km}$ NW de Los Cedros, road to Huizcolote, Lott et al. 859 (INB, MEXU, MO). Jalisco. Mpio. Autlán, 1-2 km SSE of Ahuacapan, Guzmán 910 (WIS); Nuñez 5132 (WIS); Mpio. Zapotitlán de Vadillo, Zapotitlán de Vadillo, Sanders 10820 (MO); Rancho el Jabalí, $20 \mathrm{~km} \mathrm{~N}$ of Colima in the SW foothills of the Volcan of the Colima, Vázquez 1401 (MO). Michoacán. Mpio. Arteaga, a $7 \mathrm{~km}$ al $\mathrm{N}$ de Arteaga, camino a Nueva Italia, Martínez et al. 5393 (MEXU). Mpio. Coalcoman, Coalcoman, Hinton 12834 (US); Sierra Madres, Langlassé 597 (G).

6. Mandevilla foliosa (Müll.Arg.) Hemsl., Biol. Cent.Amer., Bot. 2(10): 316. 1882. Amblyanthera foliosa Müll. Arg., Linnaea 30(4): 427-428. 1860. Laseguea foliosa (Müll. Arg.) Miers, Apocyn. S. Amer. 253. 1878. Tipo. México. México: near Mexico city, 1842 (fl.), A. B. Ghiesbreght s.n. (Holotipo: G-DC!, foto F neg. 26876!; Isotipos: F!, P!).

Trachelospermum stans A.Gray, Proc. Amer. Acad. Arts 21: 394. 1886. Secondatia stans (A.Gray) Standl., Contr. U.S. Natl. Herb. 23(4): 1165. 1924. Mandevilla stans (A.Gray) J.K.Williams, Phytologia 86(3): 179-181, 2004. Tipo. México. Rocky hills near Chihuahua, 19/10/1885 (fl., fr.), C. G. Pringle 640 (Holotipo: GH!; Isotipos: A!, CAS!, ENCB!, F!, foto F neg. 56524!, G!, K!, MA!, MIN, MO!, P-3!, US!).

Arbustos o hierbas a veces volubles $0.5-2 \mathrm{~m}$ alto, tallos puberulentos a glabros. Hojas con pecíolo (0.3-) 0.5-1.3 (-1.8) cm largo; láminas 5-13.5 (- 15.1) × 1.5-5.5 (-7) cm, elípticas, ovado-lanceoladas a obovadas, base obtusa, cuneada a subcordada, ápice agudo a acuminado, márgenes rectos, membranáceas, haz puberulento rara vez glabro, con coléteres en la base de la vena media, envés pubescente, principalmente en la venación. Inflorescencias con 3-9 (-14) flores; pedúnculo $0.2-1.5 \mathrm{~cm}$ largo; brácteas $2.5-9 \mathrm{~mm}$ largo, lanceoladas a linear-lanceoladas, escariosas, esparcida a densamente pubescentes; pedicelo $0.5-2 \mathrm{~cm}$ largo; sépalos (0.3-) 0.5-1 cm largo, lanceolados a linear-lanceolados, escariosos a foliosos, pubescentes; corola hipocraterimorfa, amarilla o amarillenta, glabra; tubo 1-1.5 × 0.3-0.4 cm, recto; lóbulos 0.6-1 $\times 0.4 \mathrm{~cm}$, obovados a oblanceolados, extendidos; estambres insertos en la parte superior del tubo, anteras 3-3.5 $\mathrm{mm}$ de largo. Folículos 7-12.5 $\times 0.3-0.5 \mathrm{~cm}$, libres, continuos a submoniliformes, glabros a finamente pubescentes, sin lenticelas; semillas 0.7-1 cm largo. Figuras 1D, 2C.

Distribución y ecología: Endémica de México (Chihuahua, Distrito Federal, Durango, Guanajuato, Guerrero, Hidalgo, Jalisco, México, Michoacán, Morelos, Nayarit, Querétaro, Sinaloa, Sonora, Veracruz; Figura 4B). Esta especie crece en los bosques tropicales caducifolios, espinosos, encino y pino, así como en matorral xerófilo y vegetación secundaria derivada de estos, en elevaciones de los 50 hasta $\operatorname{los} 2,300 \mathrm{~m}$ s.n.m. La floración ocurre de mayo a septiembre y la fructificación de julio a noviembre.

Comentarios taxonómicos. Williams (2004) reconoce como especie válida a Mandevilla stans (A.Gray) J.K.Williams, que anteriormente se consideraba como un sinónimo de M. foliosa (Woodson, 1932, Morales, 1998). Williams distingue este taxón de M. foliosa con base en la presencia de pubescencia en hojas, tallos e inflorescencias, así como una distribución disyunta restringida al norte del país. Sin embargo, se considera que $M$. stans debe ser subordinada nuevamente a sinónimo de $M$. foliosa, ya que los atributos florales permanecen invariables y la presencia de pubescencia es un atributo vegetativo que puede estar respondiendo a un gradiente de humedad y temperatura, con plantas muy pubescentes en el Norte y menos pubescentes hacia el Sur, característica observada en otras especies con similar distribución. Asimismo, la distribución de ambos taxones no muestra una clara disyunción entre las poblaciones del norte y las del sur como anteriormente se planteó (Figura 4B).

Ejemplares seleccionados: Chihuahua. Mpio. de Madera, Bajada a los Parapetos, camino al Verbanís, Benítez 1362 (IEB, MEXU); El Huaje, on Chihuahua-Cuahtemoc hwy, Knobloch 643 (MICH, MO), Canyona, mts. Near Chihuahua, Pringle 701 (B, BM, MEXU, MO, NY, US). Colima. Mpio. Minatitlán, Cerro Grande, Iltis et al. s.n. (IEB). Distrito Federal. Citado por Calderón de Rzedowski y Rzedowski (2001), pero no se encontraron ejemplares. Durango. Mpio. Tepehuanes, $18 \mathrm{~km}$ al NW de Tepehuanes, Hernández et al. 8093 (INB, MEXU), Tobar, Palmer 395 (B, E GH, MO, NY, US). Guanajuato. Mpio. San Miguel de Allende, cerca de la presa de Allende, aprox $14 \mathrm{~km}$ de San Miguel, Argüelles2617 (IEB, MEXU). Mpio. Victoria, Lagunilla 15 $\mathrm{km}$ al N de Victoria, Ventura 6928 (IEB, MEXU). Guerrero. Mpio. Taxco de Alarcón, Juliantla $8 \mathrm{~km}$ al SE rumbo a Tlamacazapa, Calónico 6154 (MEXU); $7 \mathrm{~km}$ al SE de Taxco, camino a Iguala-Taxco, Martínez 1211 (MEXU). Hidalgo. Mpio. Ajacuba, Poblado Emiliano Zapata, 19 km después de Ajacuba sobre la carretera pavimentada que va a San Agustín Tlaxiaca (de W-E), Díaz 576 (IEB, MEXU). Mpio. Jacala de Ledezma, Jacala, Taylor 810 (MO, TEX). Jalisco. Mpio. Tecolotlán, Los Ailes, Díaz 3393 (ENCB, MEXU); Mpio. Tlajomulco de Zúñiga, Cerro El Ocote, Laguna Cajititlán, de Puga 15927 (MEXU). México. 4 mi. S of Ixtapan on hwy 55 towns with Bougainvillea, Dunn et al. 20444 (MEXU, MO); Cercanía de Ixtapan de la Sal, Matuda 28795 (MEXU). Michoacán. Mpio. Erongarícuaro, Camino al Huacaplan, Puácuaro, Caballero 681 (MEXU). Mpio. Puruándiro, 9 km al SE de Puruándiro, sobre la carretera a Cuitzeo, Díaz 1146 (ENCB, IEB, MEXU). Morelos. Mpio. Yautepec, km 15 of highway Yautepec-Cuernavaca 
Road, Lundell 12499 (MEXU). Nayarit. Mpio. Ahuacatlán, A 5-11 km al S de Ahuacatlán, camino a Amatlán de Cañas, Téllez 11029 (IEB, MEXU). Querétaro. Mpio. Querétaro, a $2.7 \mathrm{~km}$ al NE de la cabecera municipal de Huimilpan, hacia la desv. a Escolásticas sobre la carr. Qro-Huimilpan, Suárez 107 (QMEX); a $3 \mathrm{~km}$ al W de La Carbonera, Zamorano 1 (QMEX). Sinaloa. Mpio. Concordia, Pitaca (La Petaca), González 289 (MEXU); $50 \mathrm{~km}$ al NE de Concordia carr. Mazatlán-Durango, Ortíz 268 (MEXU). Sonora. Mpio. Yécora, Trigo Moreno, Sierra El Chuchupate, ca $15 \mathrm{~km}$ (by air) southeast of Yecora, Devender 98-1016 (MEXU); Sierra El Chuchupate, $0.1 \mathrm{mi}$ north of Trigo Moreno, $7.1 \mathrm{mi}$ south of hwy 16 at Rancho Las Viboras, 9.4 mi east of Yécora, Fishbein et al. 3675 (MEXU). Veracruz. San Martín Tuxtla, Pastizal arriba de Santiago, Nevling 1808 (MEXU).

7. Mandevilla guerrerensis Lozada-Pérez \& N.Diego, $D a$ rwiniana 50(2): 319. 2012. Tipo: México, Guerrero, Municipio de Malinaltepec, Tres Marías, 26/06/2006 (fl.), Lozada-Pérez, J. Rojas y R. de Santiago 3161 (Holotipo FCME; Isotipos ENCB, MEXU!).

Bejuco, tallos densamente pubescentes. Hojas con pecíolo $0.5-1 \mathrm{~cm}$ de largo; láminas $5-8 \times 1.5-3.2 \mathrm{~cm}$, elípticas a estrechamente elípticas, base redondeada a subcordada, ápice largamente acuminado, margenes rectos, membranáceas, haz esparcidamente pubescente, con coléteres concentrados en la base de la vena media, envés densamente pubescente. Inflorescencias con 4-5 flores, pedúnculo de 1.2-3.5 cm de largo, brácteas 2.5-3.5 mm de largo, linear lanceoladas, escariosas, esparcidamente pubescentes, pedicelo de 1-1.5 cm de largo; sépalos 4-5 × 0.8-1 mm, lanceolados, escariosos, esparcidamente puberulentos; corola hipocraterimorfa, amarilla, glabra; tubo de 6.7-7.3 × 2.7-3 mm, recto; lóbulos 3.5-4 × 2.3-2.5 mm, ovados, ápice obtuso a redondeado, extendidos; estambres insertos en la parte media del tubo, anteras ca. $3 \mathrm{~mm}$ de largo. Folículos $18-24 \times 0.4 \mathrm{~cm}$, submoniliformes, puberulentos; semillas 1.1-1.2 de largo.

Distribución y ecología: Especie endémica del estado de Guerrero, México (Figura 4A). Crece en bosque mesófilo de montaña a elevaciones de 2,100-2,400 m s.n.m. La floración ocurre de mayo a junio-agosto y la fructificación en octubre.

Comentarios taxonómicos. Los datos descriptivos de esta especie fueron tomados principalmente de la publicación de Lozada-Pérez y Diego-Pérez (2012).

Mandevilla guerrerensis es muy parecida a M. holosericea y $M$. torosa. Con la primera presenta mucha similitud en el aspecto vegetativo y tamaño de sus flores, pero se diferencía por presentar flores glabras (interna y externamente) y lóbulos de la corola extendidos. En el caso de la segunda, ambas presentan flores de tamaño similares y lóbulos de la corola extendidos, pero $M$. guerrerensis se distingue por sus hojas membranáceas y lóbulos más pequeños; además, $M$. guerrerensis es endémica de Guerrero y $M$. torosa está pre- sente principalmente en la vertiente del Atlántico y la Península de Yucatán.

Ejemplares seleccionados: Guerrero. Mpio. Leonardo Bravo, $18 \mathrm{~km}$ delante de El Carrizal de Bravos hacia Puerto Gallo, Fonseca 361 (FCME, MEXU).

8. Mandevilla hesperia (I.M.Johnst.) A.O.Simões, Kin.Gouv. \& M.E.Endress, Novon 17(1): 88. 2007. Macrosiphonia hesperia I.M.Johnst., Proc. Calif. Acad. Sci., ser. 4, 12: 1125. 1924. Telosiphonia hesperia (I.M.Johnst.) Henrickson, Aliso 14(3): 191. 1995 [1996]. Tipo. México. Baja California Sur: Puerto Bellandra, Isla Carmen, 21/05/1921 (fl., fr.), I. M. Johnston 3807, (Holotipo: CAS!, foto INB!; Isotipo: US!).

Arbustos 0.5-2 m alto, tallos tomentosos a glabrescentes. Hojas con pecíolo 1.5-8 mm largo, láminas 1.4-4.2 × 1-4.4 $\mathrm{cm}$, ovadas, orbiculares o reniformes, base cordada u obtusa, ápice obtuso, rara vez obcordado, corto mucronado, márgenes rectos, subcoriáceas, haz lanuginoso a tomentoso, con coléteres en la base de la vena media, envés lanuginoso a tomentoso. Inflorescencias con 1 flor; pedúnculo 1-5 mm largo; brácteas 0.6-1 cm largo, ovado-lanceoladas, foliosas, pubescentes; pedícelo 2-1.2 cm largo; sépalos $0.7-1.6 \mathrm{~cm}$ largo, ovado-lanceolados a oblongo-lanceolados, foliosos, tomentosos; corola infundibuliforme, blanca, pubescente, tubo (3.5-4) 5.5-7.5 $\times$ 0.5-0.7 cm, recto, garganta $1.5-2 \times$ 0.8-1.0 cm, tubular, lóbulos 1.8-2.8 × 1.4-1.8 cm, ovadooblongos, extendidos; estambres insertos en la base de la garganta, anteras $0.8-1.0 \mathrm{~cm}$ largo. Folículos 8-15 × 0.5-0.7 $\mathrm{cm}$, libres, continuos, diminutamente pubescentes, sin lenticelas; semillas 0.8-1 cm largo. Figura $2 \mathrm{O}$.

Distribución y ecología: Especie endémica de Baja California Sur, México (Figura 4B). Esta especie crece en bosque tropical caducifolio y matorral xerófilo a elevaciones de 20 a 1,500 m. s.n.m. La floración ocurre entre agosto y enero y la fructificación de octubre a marzo.

Ejemplares seleccionados: Baja California Sur. Vicinity of Rancho Tasajera, ca $3.5 \mathrm{~km}$ northeast of San José de Agua Verde, Carter 4838 (MEXU); Isla Santa Catalina, 200-500 m al N Flores 453 (MEXU).

9. Mandevilla hirsuta (A.Rich.) K.Schum., Nat. Pflanzenfam. 4(2): 171. 1895. Echites hirsutus A.Rich., Actes Soc. Hist. Nat. Paris 1: 107 1792. Echites richardii Roem. \& Schult., Syst. Veg. 4: 391. 1819, nom. illeg. Amblyanthera hirsuta (A.Rich.) Miers, Apocyn. S. Amer. 185-186. 1878. Tipo. Guyana Francesa. Cayenne, 1792 (fl.), J. B. Le Blond 387 (Lectotipo: P-LAM! designado por Allorge-Boiteau, 1998, foto INB!; Isolectotipos: C!, F!, G-DC!, foto F neg. 26863!, P-2!).

Mandevilla denticulata S.F.Blake, Contr. Gray Herb. 52: 81. 1917. Tipo. Belice. New Haven, 8/03/1907 (fl.), M. Peck 696 (Holotipo, GH!, foto INB!; Isotipo, K!).

Bejucos, tallos pilosos a glabrescentes. Hoja con pecío- 
lo 1-3.5 cm largo; láminas (3.5-) 6.5-16 × (1.4-) 2.5-9 cm, elípticas a obovadas, base cordada a subauriculada, ápice acuminado a largo-acuminado, márgenes rectos a revolutos, membranáceas, haz esparcidamente hirsuto, con coléteres a lo largo de la vena media, envés esparcidamente hirsuto. Inflorescencias con 6-15-flores; pedúnculo 1.1-6.1 cm largo; brácteas 1-1.8 cm largo, ovado-lanceoladas, foliáceas, pubescentes; pedicelo $0.5-2 \mathrm{~cm}$ largo; sépalos $0.7-1.7 \mathrm{~cm}$ largo, elípticos a lanceolados, foliáceos, pubescentes; corola infundibuliforme, amarilla a blanquecina, la garganta rojiza, híspida a pilosa; tubo 2.2-3.8 $\times 0.3-0.5 \mathrm{~cm}$, giboso; garganta 1.5-2.5 × 1.4-2 cm, campanulada; lóbulos 1.5-2.4 × 1.4-1.8 $\mathrm{cm}$, obovados, extendidos; estambres insertos en la base de la garganta, anteras 4-5 mm largo. Folículos (6-) 8-18 × 0.3$0.4 \mathrm{~cm}$, libres, submoniliformes, hirsútulos; semillas 0.9-1.1 $\mathrm{cm}$ largo. Figuras 1E, 2G.

Distribución y ecología: En México (Chiapas, Oaxaca y Tabasco; Figura 4A), Centroamérica, islas del Caribe y en Sudamérica hasta Paraguay. Esta especie crece en el bosque tropical perennifolio y zonas de cafetales a elevaciones entre los 100 a los 300 m s.n.m. La floración ocurre en los meses de junio a abril y la fructificación entre los meses de noviembre a abril.

Comentarios taxonómicos. Especie fácil de reconocer del resto por las brácteas foliáceas, la corola infundibuliforme de color amarillo con tonos rojizos, y densamente hirsutopubescente.

Mandevilla hirsuta (Figuras 1E, 2G) cuenta con más de 20 sinónimos principalmente de Sudamérica, por lo que sólo se consideraron los de la región mesoamericana. La lista completa de estos puede revisarse en el trabajo de Morales (2007b).

Ejemplares seleccionados: Chiapas. Mpio. Ocosingo, en el vertice del río Chixoy a $90 \mathrm{~km}$ al S de Boca Lacantum, camino a Chajul, Martínez 18336 (IEB, MO). Oaxaca. Mpio. Matias Romero, Col Cuauhtémoc, terracería entre Sarabia y La Laguna, Wendt 3936 (IEB, TEX). Mpio. Santa María Chimalapa, Cafetales de arroyo de sangre, cerca de Santa María, Wendt 5612 (MEXU). Tabasco. Mpio. Huimanguillo, Km 50 de la desv. de Huimanguillo hacía Francisco Rueda, Cowan 2619 (NY, MO).

10. Mandevilla holosericea (Sessé \& Moc.) J.K.Williams, Sida 18(1): 237. 1998. Echites holosericeus Sessé et Moc., Naturaleza (México), ser. 2, 2, app. 45. 1893. Tipo. México. Michoacán: Ahualulci silvis, 10/1787-1795 (fl.), M. Sessé y J. M. Mociño 5073 (Holotipo: MA!, foto F neg. 41254!; Isotipo: $\mathrm{F}$ !).

Mandevilla syrinx Woodson, Ann. Missouri Bot. Gard. 19(1): 53-54. 1932. Tipo. México. Jalisco: Mpio. Tequila, Barranca of Tequila, 8/10/1893 (fl.), C. G. Pringle 5422 (Holotipo: MO!; Isotipos: F!, foto F neg. 56479!, GH!, MEXU!).

Mandevilla sertuligera Woodson, Ann. Missouri Bot.
Gard. 19(4): 383-384. 1932. Tipo. México. Michoacán: Rocky hills near Coru Station, 23/01/1907 (fl.), C. G. Pringle 13890 (Holotipo: US; Isotipos: CM, GH, MO, foto sitio web MO!, fotocopia, INB!, US).

Bejucos, tallos tomentulosos a glabrecentes. Hoja con pecíolo 0.2-1.1 cm largo; láminas 2.6-12 (-13.8) × 1-5.2 $(-7.1) \mathrm{cm}$, elípticas, ovadas, ovado-lanceoladas a rara vez obovadas, base cordada a subauriculada, ápice obtuso y mucronado o acuminado, márgenes rectos a revolutos, membranáceas, haz esparcidamente puberulento a glabrescente, con coléteres en la base de la vena media, envés tomentoso a tomentuloso, raramente glabro. Inflorescencias con 8-55flores; pedúnculo 3-4.7 cm largo; brácteas 3-5 mm largo, lanceoladas, escariosas, pubesentes a glabras; pedicelo 0.4-1 cm largo; sépalos 2.5-5 (-6.5-7.5) mm largo, ovados a ovado-lanceolados, escariosos, esparcidamente pubescentes; corola tubular, amarilla a amarillo-verdosa, glabra; tubo 0.5-1.1 × 0.25-0.4 cm, recto; lóbulos (2-) 3-6 × 2-3.5 $\mathrm{mm}$, oblongos a obovados, erguidos; estambres insertos en la parte media del tubo, anteras 2.5-4 mm largo. Folículos $10-30 \times 0.35-0.45 \mathrm{~cm}$, libres, continuos a submoniliformes, esparcidamente pubescentes a glabros, con o sin lenticelas; semillas 7-8 mm largo. Figuras 1G, 2E.

Distribución y ecología: Endémica de México (Colima, Guanajuato, Guerrero, Hidalgo, Jalisco, México, Michoacán, Morelos, Nayarit, Oaxaca, Puebla, Querétaro, Sinaloa; Figura 3C). Mandevilla holosericea puede encontrarse en el bosque tropical caducifolio, bosque de encino y matorral xerófilo, en elevaciones de 990 a 2,300 m s.n.m. La floración y fructificación se presenta de junio a enero.

Ejemplares seleccionados: Colima. Mpio. Colima, Rancho el jabalí, aprox. $20 \mathrm{~km} \mathrm{~N}$ de la Cd. de Colima, cerca de la Hacienda San Antonio, Rico et al. 933 (MEXU). Guanajuato. Mpio. Acámbaro, $3 \mathrm{~km}$ al NW de Irámuco, Rzedowski 52022 (IEB, MEXU); Mpio. San Miguel Allende, base del cerro Los Picachos, Díaz 5842 (IEB, MEXU). Guerrero. Mpio. Eduardo Neri, Puerto de los Tepetates, a $2 \mathrm{~km}$ al N de Amatitlán, Cruz 603 (FCME, MEXU); Mpio. Tlapa de Comonfort, en el puerto El Salado, a $7 \mathrm{Km}$ al N de Tlapa camino a Huamuxtitlán, Martinez 1077 (IEB, MEXU, MO). Hidalgo. Mpio. Zimapán, Cerro de la Cruz, al N de Zimapán, Tenorio et al. 9137 (INB. MEXU). Jalisco. Mpio. Tequila, Barranca of Tequila, Pringle 5422 (MEXU, MO). México. Mpio. Temascaltepec de González, Salitre-Cañitas, Hinton 4307 (MEXU, MO); San Lucas (del Pulque), Hinton 7176 (MEXU, MO). Michoacán. Mpio. Ziracuáretiro, Rock fields, Coru Station, Pringle 13106 (B, C, GH, K, MEXU, MO, TEX. US). Mpio. Zitácuaro, $15 \mathrm{~km} \mathrm{SW} \mathrm{de} \mathrm{Zitácuaro,}$ ca. Carretera, Ramamoorthy 4442 (IEB, MEXU). Morelos. Mpio. Cuernacava, Lava beds near Cuernavaca, Pringle 6329 (MEXU). Mpio. Xochicalco, Cerro La Bodega, Piña 141 (MEXU). Nayarit. Mpio. Nayar, $5 \mathrm{~km}$ al NW del poblado del Cerro Cangrejo, en cañada, Flores 1605 (MEXU). Oaxaca. Mpio. Santos Reyes Tepejillo, Santos Reyes Tepe- 
jillo, senda antigua para Río Boquerón y San Miguel Tlacatepec, Calzada 21305 (MEXU). Mpio. Villa de Tamazulapam del Progreso, $6 \mathrm{~km}$ SW de Villa de Tamazulapam del Proreso, camino a Villa Chilapa de Díaz, García-Mendoza et al. 2295 (MEXU). Puebla. Mpio. Jolalpan, $2 \mathrm{~km}$ al NW de San Pedro las Palmas, Razo 11 (IEB, MEXU). Mpio. Matamoros, Matamoros, Miranda 2843 (MEXU). Querétaro. Mpio. Huimilpan, Los Cues, Argüelles 1729 (MEXU); Mpio. Toliman, $14 \mathrm{~km}$ al NW de Toliman, sobre el camino a El Derramadero, Rzedowski 50164 (IEB, MEXU, QMEX). Sinaloa. Capadero, Sierra Tacuichamona, Gentry 5598 (MEXU).

11. Mandevilla hypoleuca (Benth.) Pichon, Bull. Mus. Natl. Hist. Nat., sér. 2, 20: 106. 1948. Echites hypoleucus Benth., Pl. Hartw. 23. 1839. Macrosiphonia hypoleuca (Benth.) Müll. Arg., Linnaea 30: 452. 1860. Rhodocalyx hypoleucus (Benth.) Miers, Apocyn. S. Amer. 140. 1878. Telosiphonia hypoleuca (Benth.) Henrickson, Aliso 14(3): 1851995 [1996]. Tipo. México. Guanajuato: Sin localidad, 1837 (fl.), K. T. Hartweg 193 (Holotipo: K; Isotipos: BR!, LD!, P!, W!).

Echites suaveolens M.Martens \& Galeotti, Bull. Acad. Roy. Sci. Bruxelles 11: 356. 1844, nom. illeg. non Echites suaveolens (Lindl.) A.DC. Prodr. 8: 452. 1844. Rhodocalyx suaveolens (M.Martens \& Galeotti) Miers, Apocyn. S. Amer. 139. 1878. Tipo. México. Michoacán: Cordillera, s. f. (fl.), H. Galeotti 1593, (Holotipo: BR!; Isotipo: W).

Macrosiphonia wrightii A.Gray, Syn. Fl. N. Amer. 2(1): 83. 1878. Estados Unidos. Texas: From Western Texas to El Paso, New Mexico, 05-10/1849 (fr.), C. Wright 558 (Lectotipo: GH! designado por Henrickson (1996); Isolectotipos: GH!, MO!, foto INB!, NY!, US!).

Echites uniflorus Sessé \& Moc., Naturaleza, ser. 2, 1, app. 28. 1888. Tipo. México. Sin localidad, s.f. (fl.), M. Sessé y J. M. Mociño 5069 (Holotipo: MA!; Isotipo: G!).

Arbustos o hierbas 0.1-1 m alto, rizomatosos; tallos densamente pubescentes a glabrescentes. Hojas con pecíolo 1-4 mm largo; láminas (2.2-) 3-7 × (0.4-) 0.6-1.5 (-2) cm, lineares a oblongo-elípticas, base truncada a obtusa o subcordada, ápice agudo, obtuso o apiculado, márgenes revolutos a veces ligeramente ondulados, subcoriáceas, haz pubescente, con coléteres en la base de la vena media, envés canescente tomentoso. Inflorescencias con 1-2 (-3) flores; pedúnculo (0.5-) 1-2.5 (-6.5) cm largo; brácteas 4-7 mm largo, lineares, foliosas, pubescentes; pedicelo 0.7-1.5 cm largo; sépalos (0.7-) 0.9-1.2 (-1.5) cm largo, lineares a lanceolados, foliosos, rojizos, pubescentes; corola infundibuliforme, blanca, con tintes rojizos a rosados, diminutamente pubescente, tubo (1-) 2-3 $\times 0.2-0.4 \mathrm{~cm}$, recto, garganta (1.5-) 2-2.5 (-3) $\times 0.7-1 \mathrm{~cm}$, tubular, lóbulos de (1.5-) $2.5-3 \times 1.7-2.5 \mathrm{~cm}$, obovados, extendidos; estambres insertos en la base de la garganta, anteras 0.9-1.1 cm largo. Folículos (7-) 8-11 (-15) $\times 0.3-0.5 \mathrm{~cm}$, continuos, densamente pubérulos; semillas $0.8-1 \mathrm{~cm}$ largo. Figuras 1F, 2N.
Distribución y ecología: En EUA (Texas) y México (Aguascalientes, Chihuahua, Coahuila, Durango, Guanajuato, Hidalgo, Jalisco, México, Michoacán, Nayarit, Nuevo León, Querétaro, San Luis Potosí, Sinaloa, Sonora, Tamaulipas, Veracruz y Zacatecas; Figura 4A). Se encuentra en bosque tropical caducifolio, matorral xerófilo, bosque espinoso, bosque de pino, bosque de encino, bosque de pino-encino y vegetación secundaria en elevaciones que van desde los 440 hasta los 2,600, pero principalmente entre los 1,000 y 1,800 m s.n.m. La floración y fructificación ocurre entre mayo y septiembre.

Comentarios taxonómicos. Mandevilla hypoleuca es una de las especies del género con mayor distribución en México, así como una de las que se encuentra en una gran variedad de ambientes y elevaciones. Esta especie es fácilmente reconocible por el hábito arbustivo, las hojas lineares a linear-lanceoladas y el tubo de la corola de igual o menor tamaño que la garganta (Figuras 1F, 2N).

Ejemplares seleccionados: Aguascalientes. Mpio. Aguascalientes, Aguascalientes, Bravo s.n. (MEXU). Chihuahua. Mpio. Chihuahua, $10 \mathrm{mi}$. W of General Trias off hwy 16, Dunn 905 (MEXU). Mpio. Temosachi, Nabogame Laferriere 1519 (MEXU). Coahuila. $17 \mathrm{~km}$ by winding road N of Rancho El Jardín; ca 5 km SW of Mina El Pipo, Johnston 11878 (MEXU). Durango. Mpio. Mezquital, Sombrero Quemado, La Guajolota, Solís 206 (IEB, MEXU). Mpio. Santiago Papasquiaro, $14 \mathrm{~km}$ al W de Garame de Abajo, Tenorio et al. 990 (MEXU). Guanajuato. Mpio. Cañada de Virgen, Puente los Alisos, Cano et al. 2 (IEB, MEXU). Hidalgo. Mpio. Alfajayucan, A $6 \mathrm{~km}$ al NW de Alfajayucan, Tenorio et al. 251 (IEB, MEXU). Jalisco. Mpio. Talpa, Agua Dulce, Hacienda de Huaxtla, Río Salado $30 \mathrm{~km}$ al W de Guadalajara, Puga 15568 (MEXU). México. Mpio. Tejupilco, Cerro Nanchititla, Matuda 3156 (MEXU). Mpio. Tepotzotlán, Cerro de la Cruz, $5 \mathrm{~km}$ al NW de Tepotzotlán, Rzedowski 31951 (ENCB, MEXU). Michoacán. Mpio. Morelia, cerca del Rancho Los Pastores, Díaz 2339 (IEB, MEXU). Nayarit. Mpio. Nayar, Recorrido entre el poblado y Aguamilpa y el Cerro del Colomo, Benítez 3417 (MEXU). Nuevo León. Citado por Henrickson (1996), pero no se encontraron ejemplares del estado. Puebla. Mpio. Acatlán de Osorio, Acatlán, Torres s.n. (IEB). Querétaro. Mpio. Ezequiel Montes, $4 \mathrm{~km}$ al E de Las Rosas, Zamudio 7390 (ENCB, IEB, MEXU, QMEX). San Luis Potosí. Mpio. Jesús María, Sierra de San Miguelito, $8 \mathrm{~km}$ al O de Jesús María, Rzedowski 5887 (MEXU). Sinaloa. Mpio. Mazatlán, Cerro de la Prieta, González 4670 (MEXU). Sonora. Mpio. Yécora, Along hwy 16, c. $1 \mathrm{~km}$ west of Chihuahua state line, 1.4 mi, East of Arroyo Hondo, Fishbein 3618 (MEXU). Tamaulipas. Citado por Henrickson (1996), pero no se encontraron ejemplares del estado. Veracruz. Mpio. Acultzingo, Acultzingo McKee 10882 (MEXU). Zacatecas. Mpio. Juchipila, al W de Pueblo Viejo, cerro de Piñones, ladera este, rancho de Jesús Ayala, Balleza et al. 8700 (MEXU). 
12. Mandevilla lanuginosa (M.Martens \& Galeotti) Pichon, Bull. Mus. Natl. Hist. Nat., sér. 2, 20:106. 1948. Echites lanuginosus M.Martens \& Galeotti, Bull. Acad. Sci. Roy. Bruxelles 11: 357. 1844. Rhodocalyx lanuginosus (M.Martens \& Galeotti) Miers, Apocyn. S. Amer. 139. 1878. Macrosiphonia lanuginosa (M.Martens \& Galeotti) Hemsl., Biol. Cent.-Amer., Bot. 2(10): 316. 1881. Telosiphonia lanuginosa (M.Martens \& Galeotti) Henrickson, Aliso 14(3): 189. 1996. Tipo. Mexico. Hidalgo: Croit sur les versants calcaires et schisteux du gran ravin de Mextitlan au NNE de Mexico, 18/08/i?, H. Galeotti 1594 (Holotipo: BR!).

Arbustos $0.5-1 \mathrm{~m}$ alto, tallos tomentulosos a glabrescentes. Hojas con pecíolo 1-5 mm largo; láminas 1.5-3 (-4) × 1-3 cm, ampliamente oblongas u ovadas a elípticas, base redondeada a subcordada, ápice agudo a obtuso, apiculado, margen ondulado y revoluto, a veces entero, subcoriáceas, haz pubescente, con coléteres en la base de la vena media, envés velutino-tomentoso. Inflorescencias con 1-2 flores; pedúnculo 1-3 mm largo; brácteas 5-7 mm largo, lineares a lanceoladas, foliosas, pubescentes; pedicelo $0.3-1.1 \mathrm{~cm}$ largo; sépalos (0.7-) 0.9-1.3 (-1.6) cm largo, oblongo-lanceolados, petaloides, rojizos, tomentulosos; corola infundibuliforme, blanca a blanquecina, con tintes rosados a rojizos, esparcidamente pubescente, tubo 5-8 (-10.5) $\times$ 0.5-0.6 $\mathrm{cm}$, recto, garganta 1.4-2 $(-2.5) \times 0.7-1 \mathrm{~cm}$, tubular, lóbulos 1.5- $2.5(-3.5) \times 1.3-2.3 \mathrm{~cm}$, oblongo-obovados, extendidos; estambres insertos en la base de la garganta, anteras 7-9 $\mathrm{mm}$ largo. Folículos 6-10 × 0.5-0.7 cm, continuos, pubescentes; semillas ca. $1 \mathrm{~cm}$ largo. Figuras 1I, 2Q.

Distribución y ecología: Presente en EUA (Texas) y México (Durango, Hidalgo, Nuevo León, San Luis Potosí y Tamaulipas; Figura 3B). Mandevilla lanuginosa crece en el matorral xerófilo, bosque de encino y bosque tropical caducifolio. En elevaciones desde los 270 a los 2,000 m s.n.m. la floración y fructificación ocurre entre mayo y octubre principalmente.

Comentarios taxonómicos. Para esta especie se reconocían dos variedades, la variedad típica que se distribuye principalmente al norte del país y sur de EUA, y la variedad oaxacensis distribuida al centro y suroeste de México. Ambas variedades se distinguen con base en la forma de las hojas, la longitud de los sépalos y de la corola, y la distribución disyunta (Henrickson, 1996; Alvarado-Cárdenas, 2004a). Aquí se considera que ambos taxones deben reconocerse como dos entidades específicas distintas, ya que ambas variedades tienen dimensiones de las flores que se mantienen más o menos constantes y distintas en ambos taxones (Figuras 1I, 2Q, T), además de que la forma de la hoja es más constante en oaxacensis y aunado a que la distribución sureña de ésta sugiere un claro contraste en el tipo de hábitat con respecto a la variedad típica. Por lo tanto, en este trabajo se eleva a categoría de especie a la variedad oaxacensis.

Ejemplares seleccionados: Durango. $20 \mathrm{mi}$. EastSoutheast of Durango, Marshall 2671 (MEXU). Hidalgo.
Mpio. Mezquititlán, Venados, $5 \mathrm{~km}$ al NE de Venados, González 4810 (MEXU). Nuevo León. Mpio. Aramberri, Sandia-La Soledad, Hinton 23009 (IEB, MO). Mpio. Salinas Victoria, Villaldama-Monterrey, Hinton 24289 (MEXU). San Luis Potosí. Mpio. Guadalcázar, 2 km al E del Huizache, Hiriart et al. 707. Mpio. Villa Juárez, Cerro de Huascamá, entre Huascamá (Guaxcamá) y Minas de San Rafael, Takaki 1748 (INEGI). Tamaulipas. Mpio. Jaumava, $0.5 \mathrm{~km}$ NW de La Florida, Nieto et al. 43 (INEGI). Mpio. Tula, 4 $\mathrm{km}$ al O del ejido El Salitrillo, Hiriart et al. 808 (MEXU).

13. Mandevilla macrosiphon (Torr.) Pichon, Bull. Mus. Natl. Hist. Nat., sér. 2, 20: 106. 1948. Echites macrosiphon Torr., Rep. U.S. Mex. Bound. 2(1): 158, pl. 43. 1859. Macrosiphonia macrosiphon (Torr.) A.Heller, Muhlenbergia 1(1): 2. 1900. Telosiphonia macrosiphon (Torr.) Henrickson, Aliso 14(3): 187. 1995 [1996]. Macrosiphonia berlandieri A.Gray, Syn. Fl. N. Amer. 2: 83. 1878. nom. superfl. et illegit. Tipo. Estados Unidos. New Mexico: Sin localidad, 1851-1852 (fl.), C. Wright 1664 (Lectotipo: NY! designado por Henrickson (1996); Isolectotipos: GH-2, NY-2!, P!, US!)

Arbustos $30-50 \mathrm{~cm}$ alto, rizomatosos, tallos tomentosos. Hojas con pecíolo 3-7 mm largo, láminas 1.5-5 × 0.9-3.5 $\mathrm{cm}$, ovadas, oblongo-ovadas a oblongo-elípticas, base obtusa o subcordada, ápice agudo a obtuso, márgenes revolutos y ondulados, rara vez recto, subcoriáceas, haz piloso, con coléteres en la base de la vena media, envés lanuginoso a tomentoso. Inflorescencias reducidas a 1 flor; pedúnculo ca $1 \mathrm{~mm}$ largo; brácteas 5.0-8.5 mm largo, lanceoladas, foliosas, pubescentes; pedícelo $0.5-1.0 \mathrm{~cm}$ largo; sépalos (0.7-) 1-2.5 cm largo, ovado-lanceolados a oblongo-lanceolados, foliosos, acrescentes, tomentosos; corola infundibuliforme, blanca, pubescente, tubo (4-) $6-9 \times 0.5 \mathrm{~cm}$, recto, garganta 1-2.5 $\times 0.6-0.8 \mathrm{~cm}$, tubular, lóbulos 2.5-3.7 × 1.8-3 cm, ovado-oblongos, extendidos; estambres insertos en la base de la garganta, anteras ca. $1.0 \mathrm{~cm}$ largo. Folículos 9-15 × 0.6 $\mathrm{cm}$, libres, continuos, diminutamente pubescentes; semillas 9-1.1 cm largo. Figura 2S.

Distribución y ecología: En EUA (Texas) y México (Chihuahua, Coahuila, Durango, Zacatecas; Figura 3C). Esta especie crece en el matorral xerófilo y bosque espinoso en altitudes desde los 350 a los 1,950 m s.n.m. La floración y fructificación ocurren entre los meses de mayo a septiembre.

Comentarios taxonómicos. Esta especie es muy similar morfológicamente a Mandevilla lanuginosa (Figuras 1I, $2 \mathrm{Q}$ ), con la que comparte similares longitudes de la corola (Figura 2S), así como un traslape en su área de distribución (Henrickson, 1996; Figura 3C). Sin embargo, M. macrosiphon se distingue principalmente por la forma, la mayor longitud y el color verdoso de los sépalos, los cuales son acrescentes; también se ha sugerido que M. macrosiphon genera los brotes a partir de las partes basales de los tallos o de los rizomas, a diferencia de $M$. lanuginosa que los produce de las partes aéreas (Henrickson, 1996). 
Ejemplares seleccionados: Chihuahua. Mpio. Chihuahua, Rocky hills near Chihuahua Pringle 694 (GH, NY). Mpio. Ojinaga, S de las Paredes, López s.n. (INEGI). Coahuila. Mpio. Parras de la Fuente, S of Parras, Hinton 23185 (IEB, QMEX). Mpio. San Buena Ventura, $9.5 \mathrm{~km}$ al NE de Rancho Cimarrón, Blando 81091 (INEGI). Durango. Mpio. Hidalgo, La Zarca, al NW km 270 de la carretera 45 entre Durango y Parral, González 3684 (MEXU). Zacatecas Citado por Henrickson (1996), pero no se encontraron ejemplares del estado.

14. Mandevilla mexicana (Müll.Arg.) Woodson, Ann. Missouri Bot. Gard. 19(1): 65. 1932. Amblyanthera mexicana Müll.Arg., Linnaea 30(4): 424. 1860. Amblyanthera mexicana var. pubescens Müll.Arg., Linnaea 30(4): 424. 1860. Echites mexicanus (Müll.Arg.) Miers, Apocyn. S. Amer. 205. 1878. Tipo. México. Oaxaca: prope Victoria, s. f. (fl.), W. F. Karwinsky 9 (Holotipo: LE; Isotipos: M!, W).

Amblyanthera mexicana (Müll.Arg.) Woodson var. glabra Müll.Arg., Linnaea 30(4): 424-425. 1860. Tipo. México. Oaxaca: Sin localidad, 1841-1842 (fl.), W. F. Karwinsky 476 (Holotipo: LE!; Isotipos: M!, W!).

Echites smithii Greenm., Proc. Amer. Acad. Arts 40: 29. 1904. Tipo. México. Oaxaca: Salomá, 9/08/1895 (fl.), A. L. Smith 672 (Holotipo: GH!).

Arbustos o hierbas 0.4-1.5 m alto, tallos glabros a esparcidamente puberulentos. Hoja con pecíolo 2-6 mm largo; láminas (1.2-) 2-6.6 × (0.6-) 1.2-1.8 (-2.2) cm, elípticas, ovadas a elíptico-obovadas, base obtusa a subcordada, ápice agudo, márgenes rara vez revolutos, membranáceas, haz glabro, con coléteres en la base de la vena media, envés esparcidamente puberulento a glabro. Inflorescencias con 3-9flores; pedúnculo 0.4-2 (-2.5) cm largo; brácteas 2-6 mm largo, lanceoladas, escariosas, glabras a pubescentes; pedicelo 0.4-1.3 cm largo; sépalos 4-6 mm largo, ovado-lanceolados, escariosos a foliosos, pubescentes a glabros; corola hipocrateriforme, amarilla, glabra; tubo 0.9-1.3 $\times 0.2-0.3 \mathrm{~cm}$, recto; lóbulos 0.9-1.8 $\times 0.4-0.9 \mathrm{~cm}$, obovados, extendidos; estambres insertos por arriba de la mitad del tubo, anteras $2.5-3$ $\mathrm{mm}$ largo. Folículos 6.5-10.5 × 0.3-0.4 cm, libres, continuos a submoniliformes, glabros a puberulentos, sin lenticelas; semillas 0.9-1 cm largo. Figuras 1J, 2F.

Distribución y ecología: Endémica de Oaxaca, México (Figura 3B). Esta especie se encuentra en matorral xerófilo, bosque de encino, bosque tropical caducifolio y vegetación secundaria a elevaciones entre los 1,900 a los 2,400 m s.n.m. La floración y fructificación ocurre entre mayo y octubre.

Comentarios taxonómicos. Mandevilla mexicana (Figuras $1 \mathrm{~J}, 2 \mathrm{~F}$ ) es una especie muy parecida a $M$. foliosa y a M. apocynifolia (Figura 2C, I) debido al hábito arbustivo y corola hipocraterimorfa amarilla. La primera se distingue de las anteriores por la dimensión de las flores y pedúnculos, así como la distribución restringida a la región oaxaqueña. Aunque se ha sugerido la subordinación de algunos de es- tos taxones a categorías infraespecíficas (Morales, 1998; Williams, 1999), se considera que cada uno de estos taxones son entidades independientes fácilmente reconocibles por los atributos morfológicos y distribución disyunta y restringida a la porción norte del estado de Oaxaca.

Ejemplares seleccionados: Oaxaca: Mpio. San Pedro y San Pablo Teposcolula, Cerro sobre el camino a San Pedro y San Pablo Teposcolula-San Andrés Lagunas, Cedillo et al. 779 (MEXU, MO); camino al Río Teposcolula, Lorence et al. 4591 (MEXU. MO). Mpio. Santiago Huauclilla, Santiago Huauclilla, Conzatti 1198 (MEXU).

15. Mandevilla nacapulensis (Felger \& Henrickson) A.O. Simões, Kin.-Gouv. \& M.E.Endress, Novon 17(1): 89. 2007. Telosiphonia nacapulensis Felger \& Henrickson, Aliso 14(3): 194-195, f. 4 e-j. 1995 [1996]. Tipo. México. Sonora. Cañón Nacapule, ca. 4 km al N de Bahía San Carlos, 11/08/1985 (fl., fr.), R. S. Felger y M. A. Dimmitt 85-830 (Holotipo: ARIZ; Isotipos: GH!, INB!, MEXU!, MO!).

Arbustos $0.5-1 \mathrm{~m}$ alto, rizomatosos, tallos tomentulosos a glabrescentes. Hojas con pecíolo 2-3 mm largo, láminas 1.3-2.2 $\times 0.6-1.5 \mathrm{~cm}$, ovadas a oblongo-ovadas, base obtu$\mathrm{sa}$, ápice agudo o acuminado, margenes rectos a ondulados, membranáceas, haz piloso, con coléteres en la base de la vena media, envés tomentoso. Inflorescencias reducidas a 1 flor; pedúnculo ca $1 \mathrm{~mm}$ largo; brácteas 6-7.5 mm largo, linear-lanceoladas, foliosas, pubescentes; pedícelo 0.8$1 \mathrm{~cm}$ largo; sépalos 5-9 mm largo, lanceolados, petaloides, rojizos, pubescentes; corola infundibuliforme, blanca, con tonos rojizos a rosados, pubescente, tubo $3.5-4.1 \times 0.3 \mathrm{~cm}$, garganta 1.1-1.7 × 0.5-0.8 cm, tubular, lóbulos 1.5-2 × 1.1$1.5 \mathrm{~cm}$, obovado-oblongos, extendidos; estambres insertos en la base de la garganta, anteras 7-8 mm largo. Folículos (5-) 8-11.5 $\times 0.3-0.5 \mathrm{~cm}$, libres, continuos, diminutamente pubescentes, sin lenticelas; semillas 1-1.1 cm largo largo. Figura 2R.

Distribución y ecología: Endémica de Sonora, México (Figura 3C). Mandevilla nacapulensis crece en el matorral xerófilo y bosque tropical caducifolio a elevaciones desde $\operatorname{los} 10$ a los 500 m s.n.m. La floración ocurre entre agosto y noviembre y la fructificación entre octubre y febrero.

Comentarios taxonómicos. Esta especie puede confundirse con Mandevilla brachysiphon (Figura 2P) por la forma de las hojas y similar distribución. No obstante, M. nacapulensis tiene una mayor longitud del tubo con respecto a la garganta (Figura 2R).

Ejemplares seleccionados: Sonora. Mpio. Hermosillo, Microondas Avispas, Sierra Baviso; $11 \mathrm{~km}$ by road (Mex 15) south of La Pintada, Felger 85820 (ARIZ, MEXU); Bahia Sn Pedro, Turner 79262 (ARIZ, MEXU).

16. Mandevilla oaxacana (A.DC.) Hemsl., Biol. Cent.Amer. Bot. 2(10): 316. 1882. Echites oaxacanus A.DC., Prodr. 8: 451. 1844. Amblyanthera oaxacana (A.DC.) Müll. 
Arg., Linnaea 30: 447. 1860. Mesechites oaxacanus (A.DC.) Miers, Apocyn. S. Amer. 234. 1878. Tipo. México. Oaxaca: Oaxaca, 04/1834 (fl.), G. Andrieux 248 (Holotipo: G-DC!, foto en ENCB!; Isotipos: K-2!, P-2!).

Echites glaucescens M.Martens \& Galeotti, Bull. Acad. Roy. Sci. Bruxelles 11(1): 358. 1844. Temnadenia glaucescens (M.Martens \& Galeotti) Miers, Apocyn. S. Amer. 214. 1878. Tipo. México. Oaxaca: Croit dans les bois dans les raillis de la Sierra de Yavezia et du Cerro San Felipe, s. f. (fl.), H. Galeotti 1582 (Holotipo: BR!; Isotipos:, G-DC!, K!, $\mathrm{P}-2$ !).

Mesechites hirtellulus (Kunth) Miers, Apocyn. S. Amer. 234. 1878. Tipo: México. Oaxaca: Puente de Gia, 1839 (fl.), K. T. Hartweg 492 (Holotipo: BM!, foto NY neg 652!; Isotipos: CGE, K-2!).

Mandevilla schumanniana Loes., Bull. Herb. Boissier 2: 556. 1894. Tipo. México. Oaxaca: Tlacolula, Mitla, 06/1888 (fl.), C. Seler y E. Seler 39 (Lectotipo: G! designado por Morales (1998); Isolectotipo: GH!).

Bejucos, tallos glabros. Hojas con pecíolo 0.4-2 cm largo, láminas 3-9.5 × 1-4.5 cm, elípticas a ovadas, base subcordada rara vez obtusa, ápice acuminado o agudo, margenes rectos, membranáceas, haz glabro o esparcidamente pubescente, con coléteres en la base de la vena media, envés esparcidamente pubescente a glabro. Inflorescencias con 4-8 flores; pedúnculo (1.4-) 2.2-6.5 cm largo; brácteas 2-7 mm largo, lanceoladas a lineares, escariosas, glabras; pedicelo (0.5-) 1.1-2.2 cm largo; sépalos 2.5-4 mm largo, ovados a ovado-lanceolados, glabros; corola infundibuliforme, amarilla, glabra; tubo 0.9-1.4 ×0.3-0.4 cm, recto, garganta 1-1.4 $\times 0.8-1.1 \mathrm{~cm}$, tubular a ligeramente campanulada; lóbulos 0.8-1.1 × 0.5-0.7 (-1) cm, obovados, extendidos; estambres insertos en la base de la garganta, anteras ca. $4 \mathrm{~mm}$ largo. Folículos 8-15 $\times 0.3-0.5 \mathrm{~cm}$, libres, continuos, glabros, sin lenticelas; semillas 0.9-1.1 cm largo. Figuras $1 \mathrm{~K}, 2 \mathrm{H}$.

Distribución y ecología: Endémica de Oaxaca, México (Figura 4A). Mandevilla oaxacana (Figuras 1K, 2H) crece en el bosque de encino, bosque de pino-encino, vegetación secundaria derivada de estos y rara vez en bosque tropical caducifolio, a elevaciones de 1,500 a 2,150 m s.n.m. La floración ocurre de mayo a octubre, y la fructificación de julio a noviembre.

Ejemplares seleccionados: Oaxaca: Mpio. Oaxaxa de Juárez, Oaxaca, Pringle 4662 (BM, BR, G, GH, MO, MEXU, NY). Mpio. San Francisco Telixtlahuaca, 24 km $\mathrm{N}$ de San Sebastián Sedas, hacia Cuicatlán, Alvarado et al. 190 (MEXU).

17. Mandevilla oaxacensis (Henrickson) L.O.AlvaradoCárdenas \& J.F.Morales, comb. nov. Telosiphonia lanuginosa (M.Martens \& Galeotti) Henrickson var. oaxacensis Henrickson Aliso 14(3): 191. 1996. Tipo. México. Puebla: Tlacuiloltepec et Tres Mogotes, flores, ¿?/08/1909, C. A. Purpus 3989 (Holotipo: GH!; Isotipo: NY!).
Arbustos 0.2-1 m alto, tallos tomentulosos a glabrescentes. Hojas con pecíolo 1-3 mm largo; láminas 1.5-4 × 0.6$2.5 \mathrm{~cm}$, ampliamente oblongas u ovadas a elípticas, base redondeada a subcordada, ápice agudo a obtuso, márgenes a menudo ondulados y/o revolutos, subcoriáceas, haz pubescente, con coléteres en la base de la vena media, envés velutino-tomentoso. Inflorescencias con 1-2 flores; pedúnculo 1-3 mm largo; brácteas 5-7.5 mm largo, lineares a lanceoladas, foliosas, pubescentes; pedicelo de $0.7-1.1 \mathrm{~cm}$ largo; sépalos (0.7-) 0.9-1.5 cm largo, oblongo-lanceolados, petaloides, rojizos, pubescentes; corola infundibuliforme, blanca a blanquecina, con tintes rosados a rojizos, esparcidamente pubescente, tubo (2.8-) 3.4-5 × 0.3-0.4 cm, recto, garganta (1.2-) 1.8-2.5 × 0.7-0.8 cm, tubular, lóbulos 1.5-3 × 1.5-2.3 $\mathrm{cm}$, oblongo-obovados, extendidos; estambres insertos en la base de la garganta, anteras $0.7-1 \mathrm{~cm}$ largo. Folículos 6-10× 0.4-0.5 cm, continuos, pubescentes, sin lenticelas; semillas ca. $1 \mathrm{~cm}$ largo. Figura 2T.

Distribución y ecología: Endémica de México (Guanajuato, Guerrero, Hidalgo, Oaxaca, Puebla y San Luis Potosí; Figura 3A). Esta especie crece en el matorral xerófilo y bosque tropical caducifolio, a elevaciones de 1,740 a 1,950 m s.n.m. La floración ocurre entre junio y agosto, y la fructificación de julio a octubre.

Comentarios taxonómicos. Esta especie se reconocía como variedad de Mandevilla lanuginosa (Henrickson, 1996; Alvarado-Cárdenas, 2004a). Aquí se eleva a la categoría de especie a la variedad oaxacensis, ya que los atributos de la forma de las hojas y las dimensiones de las flores se mantienen más o menos constantes y distintas de la variedad típica. Asimismo, la distribución de oaxacensis, más al centro y sur del país, sugiere un claro contraste en el hábitat con respecto a la variedad típica.

Ejemplares seleccionados: Guanajuato. Mpio Guanajuato, Cañada de la Virgen, Cano 91 (MEXU). Guerrero. Mpio. Ahuacuotzingo, 4 km de la desviación a Ahuacuotzingo, Diego et al. 7139 (FCME); $6 \mathrm{~km}$ al E de Ajuatetla, Valencia et al. 262 (FCME, MEXU). Hidalgo. Mpio. Tasquillo, Cuesta de Texquedo, Hernández 3631 (MEXU). Mpio. Tecozautla, Táxido, Gómez 463 (IEB). Oaxaca: Mpio. Villa Chilapa de Diaz, $5 \mathrm{~km}$ NE de Villa Chilapa de Díaz, Campos 5216 (MEXU); 8 km NE de Santa María Chilapa de Díaz-Tamazulapan del Progreso, Rzedowski 34831 (ENCB, MEXU). Puebla. Mpio. Izúcar de Matamoros, $16 \mathrm{~km}$ al SE de Raboso, parteaguas de la "Cuenca" Vistahermosa, Guízar 1319 (ENCB, MEXU). San Luis Potosí. Minas de San Rafael, Purpus 5206 (MEXU).

18. Mandevilla subsagittata (Ruiz \& Pav.) Woodson, Ann. Missouri Bot. Gard. 19(1): 69-70. 1932. Echites subsagittatus Ruiz \& Pav., Fl. Peruv. Prodr. 2: 19. 1799. Tipo. Perú. Huanuco: Cuchero, 1778-1788 (fl.), H. Ruiz y J. A. Pavón 11/56 (Holotipo: MA!, foto F neg. 29216!; Isotipo: F!).

Echites secundiflorus A.DC., Prodr. 8: 457. 1844. Tem- 
nadenia secundiflora (A.DC.) Miers, Apocyn. S. Amer. 211. 1878. Tipo. México. Habitat in calidioribus Novae Hispaniae locis, 08/1787-1803 (fl.), M. Sessé y J. M. Mociño s.n. (Holotipo: G!, foto F neg. 30762!).

Echites jasminiflorus M.Martens \& Galeotti, Bull. Acad. Roy. Sci. Bruxelles 11(1): 357-358. 1844. Mesechites jasminiflorus (M.Martens \& Galeotti) Miers, Apocyn. S. Amer. 235. 1878. Tipo. México. Veracruz: l'hacienda del Mirador, s. f. (fl.), H. Galeotti 1575 (Holotipo: BR!; Isotipo: P, foto INB!).

Echites secundus Sessé \& Moc., Fl. Mexic. 44. 1887. Tipo. México: habitat in calidioribus Novae Hispaniae locis, s. f. (fl.), M. Sessé y J.M. Mociño 5174 (lectotipo: MA! designado por Morales (1998), foto F neg 41256!).

Echites cuspidiferus S.F.Blake, Contr. Gray Herb. 52: 79-80. 1917. Tipo. Belice. Cayo: Pine ridge near Manatee Lagoon, 11/06/1905 (fl, fr), M. E. Peck 35 (Holotipo: GH!; Isotipo: $\mathrm{K}$ !).

Bejucos, tallos glabros a pilosos. Hojas con pecíolo (0.2-) 0.5-1.5 cm largo; láminas (2-) 3-10 × 0.5-3.5 cm, elípticas, oblongas o lanceoladas, a veces obovadas a oblanceoladas, base cordada, astada a auriculada, ápice agudo o acuminado, márgenes rectos o revolutos, membranáceas, haz esparcidamente pubescente, rara vez glabro, con coléteres a lo largo de la vena media, envés pubescente, rara vez glabro. Inflorescencias con (4-) 8-15 (-35) flores; pedúnculo 0.9-3.7 cm largo; brácteas 2-5 mm largo, ovado-lanceoladas, escariosas, pubescentes; pedicelo 3-7 $\mathrm{mm}$ largo; sépalos 1.5$3.5 \mathrm{~mm}$ largo, ovado-lanceolados, escariosos, pubescentes; corola hipocrateriforme, amarilla a anaranjada, ocasionalmente la garganta rojiza, glabra a pubescente; tubo 2-3.5 $\times$ 0.2-0.3 cm, giboso; lóbulos 1-1.6 × 0.6-0.9 cm, obovados a oblongos, extendidos a ligeramente reflexos; estambres insertos en la parte apical del tubo, anteras 4-5 mm largo. Folículos 8-22.5 $\times 0.2 \mathrm{~cm}$, libres, moniliformes, glabros, sin lenticelas; semillas 6-8 mm largo. Figuras 1L, 2J.

Distribución y ecología: Presente en México (Campeche, Chiapas, Guerrero, Hidalgo, Jalisco, Michoacán, Morelos, Nayarit, Oaxaca, Puebla, Querétaro, Quintana Roo, San Luis Potosí, Sinaloa, Tabasco, Tamaulipas, Veracruz, Yucatán; Figura 3B), Centroamérica y Trinidad. En Sudamérica, en los países de Colombia, Venezuela, Ecuador y Perú. Esta especie se encuentra creciendo en el bosque tropical caducifolio, el bosque tropical subcaducifolio y bosque de encino y pino. En altitudes desde los 0 a los 1,600 m s.n.m., pero principalmente por debajo de los $1,000 \mathrm{~m}$ s.n.m. La floración y fructificación ocurre todo el año, pero principalmente entre mayo y octubre.

Comentarios taxonómicos. Mandevilla subsagittata (Figura $1 \mathrm{~L}$ ) es muy parecida a $M$. villosa (Figura 1O) en la forma de las hojas, la corola y los frutos, pero se distingue de ésta última por que no presenta brácteas foliosas.

Para esta especie se consideraba que el colector del holotipo de Echites secundiflorus era J. Pavón, se corrigió esta información y se agregó a Sessé y Mociño como colectores del holotipo.

Ejemplares seleccionados: Campeche. Mpio. Calkiní, 4 km al O de Tanku'che rumbo al Remate, Durán et al. 1363 (MEXU, XAL); Mpio. Hopelchén, 3 km al SW de Kankabchén, Ortíz et al. 569 (MEXU, XAL). Chiapas. Mpio. Ocosingo, A $16 \mathrm{~km}$ al NW de Boca Lacantum camino a Palenque, Martínez et al. 16444 (IEB, MEXU). Mpio. Palenque, Javalinero Palenque, Matuda 3651 (MEXU) Guerrero. Mpio. Chilpancingo de los Bravo, El Rincón de la Via, Diego et al. 4379 (FCME, MEXU); Rincón Viejo, Kruse 800 (FCME, MEXU). Hidalgo. Mpio. Tenango de Doria, $5 \mathrm{~km}$ hacia S. Bartolo, al NE de Tenango de Doria, Hernández 3346 (MEXU). Jalisco. Mpio. Cabo Corrientes, $9.8 \mathrm{~km}$ al W de El Tuito, Magaña 372 (MEXU). Mpio. La Huerta, ca. $11 \mathrm{~km}$ al E de la carr. de Puerto vallarta-Barra de Navidad, antiguo camino a Nacastillo, parte alta de la Estación, Lott 1385 (MEXU). Michoacán. Mpio. La Huacana, Sierra las Cruces, Cañada Las Cruces, Steinmann et al. 4563 (IEB, MEXU). Morelos. Mpio. Cuernavaca, Cañon de Lobos, Miranda 1653 (MEXU). Nayarit. Mpio. Nayar, Arroyo de los Bueyes, Benítez 3868 (MEXU). Oaxaca. Mpio. San Miguel del Puerto, $500 \mathrm{~m}$ al noroeste del Rancho San Agustín, sobre la brecha a la finca El Faro, Saynez et al. 2482 (MEXU, SERO). Puebla. Mpio. Pahuatlán, Camino de Pahuatlan a Huauchinango, Miranda 3693 (MEXU). Querétaro. Mpio. Jalpa de Serra, $+3 \mathrm{~km}$ al E de Tanchanaquito, Carranza 3359 (ENCB, IEB, MEXU, QMEX); 2-3 km al N de Rancho Nuevo, Servín 1160 (ENCB, IEB, MEXU, QMEX). Quintana Roo. Mpio. Adolfo de la Huerta, A $4.87 \mathrm{~km}$ al SSE de Othón P. Blanco, Alvárez et al. 10550 (MEXU, QMEX). Mpio. Felipe Carrillo Puerto, Tixcacal Guardia, Ucán 4073 (MEXU, XAL). San Luis Potosí. Mpio. San Antonio, San Antonio, Alcorn 1757 (MEXU). Sinaloa. Mpio. Concordia, $1-2 \mathrm{~km} \mathrm{~N}$ of Copala on small mining road from Mexican Highway 40, Breedlove 43793 (MEXU). Tabasco. Mpio. Huimanguillo, km 10.2 de Huimanguillo hacia Estación Chontalpa en la carr. Huimanguillo-Malpaso, Cowan et al. 3058 (MEXU). Tamaulipas. Citado por Rzedowski y Calderón de Rzedowski (1998). Veracruz. Mpio. Emiliano Zapata, La Laja, entre carril Falso-Pinoltepec, a 900 m de la carr. Jalapa-Veracruz, Sousa 4832 (MEXU, XAL); Mpio. Xalapa-Enríquez, SE de Xalapa, Coatepec to Las Trancas, Taylor 2272 (DUKE, ENCB, INB). Yucatán. Mpio. Hopelchén, camino blanco entre Kancobenchén y Chunchintok, Chan 40423 (MEXU, XAL); Mpio. Oxkutzcab, Xul, ruderal camino Xul Yaxa Chen, May 131 (MEXU, XAL).

19. Mandevilla subsessilis (A.DC.) Woodson, Ann. Missouri Bot. Gard. 19(1): 59. 1932. Echites subsessilis A.DC., Prodr. 8: 451. 1844. Tipo. México: Sin localidad, s. f. (fl.), M. Sessé y J. M. Mociño s.n. (Holotipo: G-DC!, foto F neg 34141!; Isotipo: MA!).

Mandevilla platydactyla Woodson, Ann. Missouri Bot. 
Gard. 19(1): 55-56. 1932. Tipo. México. Oaxaca: Tolaga, 06/1842 (fl.), C. Liebmann 11986 (Holotipo: C!; Isotipo: US!).

Mandevilla mollis Lundell, Contr. Univ. Michigan Herb. 7: 46-47. 1942. Tipo. México. Chiapas: Santa Rosa, near Escuintla, 20/06/1941 (fl.), E. Matuda 4240 (Holotipo: MICH!; Isotipos: CAS!, EAP-2, F!, LL-2!, MO!, NY!, TEX!, US!).

Bejucos, tallos tomentosos a esparcidamente tomentosos. Hojas con pecíolo 2-5 mm largo; láminas 5-22 × 2.4-10.5 $\mathrm{cm}$, elípticas ovado-lanceoladas a obovadas, base obtusa a cordada, ápice acuminado, márgenes rectos, membranáceas, haz glabro a pubescente, con coléteres en la base de la vena media, envés tomentoso a tomentuloso, rara vez glabro. Inflorescencias con 11-15-flores; pedúnculo 1-6 (-12) cm largo; brácteas (0.3-) 0.5-1.2 (-1.5) cm largo, lineares a ovado-lanceoladas, verdosas, pubescentes; pedicelo 0.6-2 (-3.2) cm largo; sépalos 0.6-1.3 cm largo, ovados a oblongo-lanceolados u obovados, foliosos, verdosos; corola hipocrateriforme, amarillenta, glabra; tubo $1.3-1.9 \times$ ca. $0.3 \mathrm{~cm}$, recto; lóbulos 0.45-1 × 0.5-0.65 cm, obovados, extendidos a ligeramente reflexos; estambres insertos en la parte apical del tubo, anteras ca. $5 \mathrm{~mm}$ largo. Folículos 20.5-30 × 0.2-0.4 $\mathrm{cm}$, libres o rara vez fusionados, continuos, glabros, con o sin lenticelas; semillas 0.9-1 cm largo. Figuras 1M, N, 2K.

Distribución y ecología: Presente en México (Chiapas, Guerrero, Michoacán, Oaxaca y Puebla; Figura 3C), Belice, El Salvador y Guatemala. Esta especie crece en bosque tropical caducifolio, tropical subperennifolio, de galeria y de pino-encino. En altitudes que van de los 750 a los 2,000 m s.n.m.

Comentarios taxonómicos. Mandevilla subsessilis (Figuras $1 \mathrm{M}, \mathrm{N}, 2 \mathrm{~K}$ ) se puede confundir con M. tubiflora (Figuras $1 \mathrm{P}, 2 \mathrm{~L})$ por las flores hipocraterimorfas y estambres insertos cerca del ápice del tubo, pero puede reconocerse de ésta por las hojas subsésiles, las brácteas y los sépalos comúnmente foliosos. Para esta especie se consideraba que el colector del holotipo de Echites subsessilis era J. Pavón, se corrigió esta información y se agregó a Sesse y Mociño como colectores del holotipo.

Ejemplares seleccionados: Chiapas. Mpio. Tenejapa, Río Seco Cruz Pilal, Méndez 5028 (MEXU, MO). Mpio. Tzimol, ca. $3 \mathrm{~km}$ SE of Tzimol, Hampshire et al. 1145 (BM, MEXU, MO). Guerrero. Mpio. Chilpancingo de Bravo, Agua de Obispo, Diego et al. 2075, 7460 (FCME, MEXU). Michoacán. Citado por Diego-Pérez (2004), pero no se encontró un ejemplar de respaldo. Oaxaca. Mpio. San Miguel del Puerto, Zimatlán, $4.5 \mathrm{~km} \mathrm{~N}$ del Puente, por la Brecha a Xadaní, Salas et al. 1844 (MEXU, SERO); Mpio. Villa Sola de Vega, NE de Sola de Vega, Webster et al. 13045 (MO). Puebla. Mpio. Tepexi de Rodríguez, Paraje Cuixosto, también conocido como Agua Chiquita, Guizar et al. 4751 (MEXU).

20. Mandevilla torosa (Jacq.) Woodson, Ann. Missouri Bot. Gard. 19(1): 64-65. 1932. Echites torosus Jacq. Enum.
Syst. PI. 13. 1760. Amblyanthera torosa (Jacq.) Müll.Arg., Linnaea 30: 446. 1860. Echites torulosus L. Sp. Pl. ed. 2. 307. 1762. Mesechites torulosus (L.) Miers, Apocyn S. Am. 229. 1878. Tipo. Jamaica. Jacquin, Select. Stirp. Amer. Hist, t. 27.1763 (Lectotipo, designado por Morales (1998)).

Amblyanthera karwinskii Müll.Arg., synon. nov. Linnaea 30: 426-427. 1860. Echites karwinskii (Müll.Arg.) Miers, Apocyn. S. Amer. 206. 1878. Mandevilla karwinskii (Müll.Arg.) Hemsl., Biol. Cent.-Amer., Bot. 2(10): 316. 1882. Tipo. México. In Mexico meridionali, s. f. (fl.), $W$. F. Karwinski 473 (Lectotipo: M! designado por Morales (1998), foto INB!; Isolectotipo: LE!).

Echites coulteri S.Watson, Proc. Am. Acad. Arts 18: 113. 1883. Tipo. México. Coahuila. Sin localidad, s. f. (fl.), $T$. Coulter 957 (Lectotipo, designado por Morales (1998): MO!; Isolectotipos: CGE!, G!, GH!, K-3!, NY!).

Bejucos o arbustos a veces trepadores, tallos esparcidamente puberulentos a glabros. Hoja con pecíolo $0.1-1 \mathrm{~cm}$ largo, láminas (1-) 1.5-7(9) $\times 0.5-3 \mathrm{~cm}$, elípticas a lanceoladas u oblongas a espatuladas, base atenuada, obtusa, o subcordada, ápice agudo o obtuso y mucronado, márgenes revolutos, membranáceas a subcoriáceas, haz estrigósulo a glabro, con coléteres en la base de la vena media, a veces ausentes, envés puberulento a glabro. Inflorescencias con (3-) 5-11-flores; pedúnculo (0.4-) 1.5-6 cm largo; brácteas 2-4 mm largo, ovado-lanceoladas, escariosas, pubescentes o glabras; pedicelo 0.4-1.5 cm largo; sépalos (1.5-) 3-5 mm, ovado-lanceolados, escariosos, pubescentes o glabros; corola hipocrateriforme, amarilla a amarillenta, glabra; tubo (0.4-) 0.6-1 (-1.5) × 0.1-0.2 cm, recto; lóbulos 4-8 × 3-6 $\mathrm{mm}$, obovados a espatulados, extendidos; estambres insertos en la parte media del tubo, anteras 2-2.5 mm largo. Folículos 5-18.5 × 0.4-0.5 cm, libres, submoniliformes, glabros, sin lenticelas; semillas 0.8-1 cm largo. Figuras 1H, 2D.

Distribución y ecología: En México (Campeche, Chiapas, Coahuila, Guanajuato, Hidalgo, México, Nuevo León, Querétaro, Quintana Roo, San Luis Potosí, Tamaulipas, Veracruz y Yucatán; Figura 3A), Jamaica y Honduras. Esta especie crece en una gran variedad de ambientes, principalmente en el bosque tropical caducifolio, se desarrolla entre los 0 a los 2,850 m s.n.m. La floración y fructificación ocurre en los meses de abril a noviembre.

Comentarios taxonómicos. Esta especie se ha considerado muy parecida y cercanamente emparentada a Mandevilla karwinskii (Morales, 1998; Rzedowski y Calderón de Rzedowski, 1998; Williams, 1999), y se diferenciaba con base en el hábito de la planta, la forma de las hojas y los frutos, y el tamaño de las flores (Woodson, 1932, 1933, 1938; Morales, 1998). La observación del material de herbario y el estudio de poblaciones en el campo permitió evaluar la gran variación de estos atributos en los individuos de ambas especies a lo largo de su distribución, así como el traslape en los caracteres que se emplean para reconocerlas, como la forma de vida, el tamaño de las flores y la forma de los 
folículos. Aquí se considera que ambos taxones presentan límites muy difusos para poder separarlos, por lo que se subordina a $M$. karwinskii como un sinónimo de M. torosa (Figuras $1 \mathrm{H}, 2 \mathrm{D})$. La gran variación vegetativa y floral de $M$. torosa requiere la aplicación de herramientas morfológicas más finas y/o moleculares que permita probar si se trata de una especie o de un complejo de especies.

Ejemplares seleccionados: Campeche. Mpio. Hopelchén, 3 km al S de Hopelchén, Gutíerrez 4961 (MEXU). Chiapas. Mpio. Tuxtla Gutíerrez, Carretera arriba Chacona (NO Tuxtla G.), Miranda 5444 (MEXU). Coahuila. Mpio. Parras de la Fuente, $9 \mathrm{~km}$ south of Parras on Sierras Negras, Stanford et al. 191 (MO). Mpio. Castaños, San Lázaro, Rocky slopes of El Puerto de San Lázaro, Lyle et al. 150 (MO). Guanajuato. Mpio. Atarjea, Cuicillos, Ventura 8279 (IEB, MEXU). Hidalgo. Mpio. Cardonal, $3 \mathrm{~km}$ al N de San Cristóbal, Medrano et al. 9427 (MEXU); Mpio. Ixmiquilpan, near Ixmiquilpan, Purpus 1392 (GH, MO). México. Above Iturbide, Hinton 17948 (MO). Nuevo León. Mpio. Galeana, Hacienda Pablillo, Taylor 119 (MO, TEX). Sierra Madre above Monterrey, Pringle 8743 (MEXU, MO). Querétaro. Mpio. Landa de Matamoros, $11 \mathrm{~km}$ al W de Tilaco, Fenández et al. 3425 (ENCB, IEB, MO); Hoyo del Lodo, González 15 (ENCB, IEB, QMEX). Quintana Roo. Mpio. Cancún, a $1 \mathrm{~km}$ de Xel-Ha, Cabrera et al. 3513 (MEXU). San Luis Potosí. Mpio Tamazunchale, North of Tamazunchale, Dunn et al. 23097 (MO); Charcas, Lundell 5321 (MICH. MO); Minas San Rafael, Purpus 5213 (F, MO, NY, US). Tamaulipas. Mpio. Aldama, Sierra de Tamaulipas: region of Rancho Las Yucas, Dressler 2358 (MO); $34.2 \mathrm{~m} \mathrm{~S}$ of border between Tamps \& N.L. on hwy 85, Seigler 12188 (MEXU). Veracruz. Carrizal, Nevling et al. 2368 (MEXU, MO); Mpio. Dos Ríos, La Bocana de Actopan, Ventura 10491 (ENCB, MEXU, MO). Yucatán. Mpio. Cacalchén, a $3 \mathrm{~km}$ al N de Cacalchén, sobre el camino a Motul, Cabrera et al. 9482 (MEXU, MO).

21. Mandevilla tubiflora (M.Martens \& Galeotti) Woodson, Ann. Missouri Bot. Gard. 19(1): 52. 1932. Echites tubiflorus M.Martens \& Galeotti, Bull. Acad. Roy. Sci. Bruxelles 11(1): 358. 1844. Amblyanthera tubiflora (M.Martens \& Galeotti) Müll.Arg., Linnaea 30: 423. 1860. Tipo. México. Veracruz: near Xalapa, 07/1844 (fl.), H. Galeotti 1579 (Holotipo: K, foto INB!; Isotipo: P!).

Echites cobanensis Donn.Sm., Bot. Gaz. 40(1): 6. 1905. Tipo. Guatemala. Alta Verapaz: Cobán, 08/1904 (fl), $H$. Tuerckheim 8709 (Holotipo: US!; Isotipo: NY!).

Mandevilla donnell-smithii Woodson, Ann. Missouri Bot. Gard. 19(1): 54-55. 1932. Tipo. Guatemala. Santa Rosa: Cerro Gordo, 08/1892 (fl.), E. Heyde y E. Lux 3993 (Holotipo: GH!; Isotipos: B, K!, foto INB!, NY!, US!).

Bejucos, tallos puberulentos a glabros. Hojas con pecíolo 0.4-2.7 cm largo, láminas 2-11 × 0.7-4.5 (-6.5) cm, elípticas, ovadas a ovado-lanceoladas, base obtusa a cordada, ápice acuminado, márgenes rectos o revolutos, firmemente membranáceas a subcoriáceas, haz puberulento a glabro, con coléteres en la base de la vena media, envés tomentoso, rara vez glabro. Inflorescencias con 7-24-flores; pedúnculo (0.4-) 2.5-7 (-11.5) cm largo; brácteas 2-4 mm largo, ovadolanceoladas, escariosas, pubescentes; pedicelo $0.5-1.2 \mathrm{~cm}$ largo; sépalos 2-3.5 mm largo, ovado-lanceolados, escariosos, pubescentes; corola hipocrateriforme, amarilla o amarillenta, glabra; tubo $1.2-2 \times$ ca. $0.2-0.3 \mathrm{~cm}$, recto; lóbulos 2.5-6 $\times 2-3.5 \mathrm{~mm}$, obovados, extendidos; estambres insertos por arriba de la mitad del largo del tubo, anteras ca. $3 \mathrm{~mm}$ largo. Folículos $15-18 \times 0.2 \mathrm{~cm}$, libres, continuos a submoniliformes, glabros, sin lenticelas; semillas 8-9 mm largo. Figuras 1P, 2L.

Distribución y ecología: En México (Chiapas, Guerrero, Michoacán, Oaxaca, Sinaloa y Veracruz; Figura 4B), El Salvador, Guatemala, Honduras y Nicaragua. Mandevilla tubiflora crece en los bosques de encino, bosque tropical caducifolio, matorral xerófilo y vegetación secundaria. Esta especie crece entre los 600 y los 1,800 m s.n.m. La floración y fructificación ocurren principalmente entre los meses de junio y octubre.

Ejemplares seleccionados: Chiapas. Mpio. Tuxtla Gutíerrez, at El Sumidero, $22 \mathrm{~km}$ N of Tuxtla Gutierrez, Breedlove 27268 (MO). Mpio. Villa Corzo, Ejido Sierra Morena, al W del poblado, Alvarado et al. 289 (MEXU, MO). Guerrero. Mpio. Atoyac de Alvárez, El Ranchito 10 km del Molote, Diego 5886 (FCME, IEB, MEXU). Mpio. Chilpancingo de los Bravo, 7 km al W de Mazatlán, Fonseca 1694 (FCME, IEB, MEXU). Michoacán. Mpio. Aquila, en El Mirador, a $3 \mathrm{~km}$ al W de la desv. a Aquila, Martínez et al. 4490 (INB, MEXU). Oaxaca. Mpio. San Miguel Suchixtepec, San Miguel Suchixtepec, Tenorio et al. 18395 (INB, MEXU). Santo Domingo Telixtlahuaca, entrando al Ocotal, lado derecho de arroyo por la ladera poniente de Cerro Guiengola, Torres et al. 276 (MEXU, MO); Sinaloa. Mpio. San Ignacio, Agua Fría, González s.n. (MEXU). Veracruz. Mpio. Teocelo, Teocelo, Ventura 10640 (ENCB, MO). Mpio. Zacualpan, Zacualpan and vic., Purpus 1935 (B, F, GH, MO, NY, US).

22. Mandevilla villosa (Miers) Woodson, Ann. Missouri Bot. Gard. 19(1): 70. 1932. Laseguea villosa Miers, Apocyn. S. Amer. 250-251. 1878. Tipo. Nicaragua. Sin localidad, 1848 (fl), B. C. Seemann 95 (Holotipo: BM!; Isotipo: K!).

Echites comosus O.Kuntze, Revis. Gen. Pl. 2: 414. 1891. Tipo. Panamá: Gale, s. f. (fl), O. Kuntze 1891 (Lectotipo: NY! designado por Morales (2005), fotocopia INB!).

Bejucos, tallos pilosos a glabrecentes. Hojas con pecíolo 0.6-2 cm largo; láminas (2.2-) 4-7.5 × 2-4 cm, elípticas a obovadas, base obtusa a subcordada, ápice agudo a acuminado, márgenes rectos, haz puberulento a glabro, con coléteres a lo largo de la vena media, envés piloso, raramente glabro, subcoriáceas a coriáceas. Inflorescencias con 7-16flores; pedúnculo 0.8-2 cm largo; brácteas 1.2-2.9 (-3.5) cm 
largo, ovado-lanceoladas a lanceoladas, foliáceas; pedicelo 3-5 mm; sépalos 1-2 mm largo, ovado-lanceolados, escariosos, pubescentes; corola hipocrateriforme, amarilla, rojizo en el interior, pilosa a glabra; tubo $1.8-2.9 \times 0.5-0.85 \mathrm{~cm}$, giboso; lóbulos 1.4-1.9 × 1-1.3 cm, obovados, extendidos a reflexos; estambres insertos en el ápice del tubo, anteras 3-4 mm largo. Folículos (9.5-) 12-16 × 0.4-0.6 cm, libres, moniliformes, esparcidamente pubescentes, sin lenticelas; semillas 7-8 mm largo. Figuras 1O, 2M.

Distribución y ecología: Presente en México (Chiapas y Quintana Roo; Figura 4B), y de Centroamérica a Colombia y Venezuela. Mandevilla villosa crece en el bosque perennifolio y subperennifolio en elevaciones de los 680 a los 800 m s.n.m. La floración y fructificación ocurre entre los mese de julio a noviembre.

Ejemplares seleccionados: Chiapas: Mpio. Escuintla, Castaña, Matuda 1791 (MEXU, MO); Mpio. Tonalá, cerro Bernal 21 km South of Tonalá, Breedlove 38125 (MEXU). Quintana Roo. Mpio. Felipe Carrillo Puerto, San Andrés, $3.5 \mathrm{~km}$ hacia Noh Cah, Balam 322 (MEXU).

\section{Agradecimientos}

Extendemos nuestro agradecimiento a todo el personal de los herbarios consultados por todas las facilidades prestadas. Al Dr. Fernando Chiang por su ayuda al resolver la problématica taxonómica de Mandevilla apocynifolia. A Verónica Juárez-Jaimes y Rosalinda Medina por la revisión del manuscrito y sus atinados comentarios en la mejora del mismo. Al C. Diego Alvarado-Cárdenas por la captura del material de herbario en la base de datos. Al Dr. Victor Steinmann y Yocupitzia Ramírez por facilitar las fotos de $M$. holosericea. Agradecemos también a Victor Steinmann, André Simões y a un revisor anónimo sus atinados comentarios.

\section{Literatura citada}

Allorge-Boiteau L. 1998. New combinations in Odontadenia and Mandevilla (Apocynaceae). Phytologia 84:304-306.

Alvarado-Cárdenas L.O. 2004a. Flora del Valle de TehuacánCuicatlán 38. Apocynaceae. Instituto de Biología, Universidad Nacional Autónoma de México, México, D.F.

Alvarado-Cárdenas L.O. 2004b. Apocináceas. In: GarcíaMendoza A.J., Ordóñez D.M.J. y Briones-Salas M. Eds. Biodiversidad de Oaxaca, pp. 171-176, Instituto de Biología, Universidad Nacional Autónoma de México, Fondo Oaxaqueño para la Conservación de la Naturaleza, World Wildlife Fund, México, D.F.

Calderón de Rzedowski G. y Rzedowski J. 2001. Flora fanerogámica del Valle de México. Instituto de Ecología A.C., Centro Regional del Bajío. Comisión Nacional para el Conocimiento y Uso de la Biodiversidad, Pátzcuaro.

De Candolle A.P. 1844. Prodromus Systematis Regni Vegetabilis. Vol. 8. Fortin Masson. Paris.
Diego-Pérez N. 2004. Apocynaceae. Flora de Guerrero 20. Facultad de Ciencias, Universidad Nacional Autónoma de México, México, D.F.

Endress M.E., Sennblad B., Nilsson S., Civeyrel L., Chase M.W., Huysmans S., Grafstrom E. y Bremer B. 1996. A phylogenetic analysis of Apocynaceae s. str. and some related taxa in Gentianales: a multidisciplinary approach. Opera Botanica Belgica 7:59-102.

Endress M.E. y Bruyns V.P. 2000. A revised classification of the Apocynaceae s.1. The Botanical Review 66:1-56.

Juárez-Jaimes V., Alvarado-Cárdenas L.O. y Villaseñor J.L. 2007. La familia Apocynaceae sensu lato en México: diversidad y distribución. Revista Mexicana de Biodiversidad 78:459-482.

Henrickson J. 1996. Studies in Macrosiphonia (Apocynaceae): Generic recognition of Telosiphonia. Aliso 14:179-195.

Holmgren P.K., Holmgren N.H. y Barnett L.C. 1990. Index herbariorum. New York Botanical Garden, Nueva York.

Lozada-Pérez L. y Diego-Pérez N. 2012. Mandevilla guerrerensis (Apocynaceae, Apocynoideae), una nueva especie de México. Darwiniana 50:318-322.

Morales F.J. 1998. A synopsis of the genus Mandevilla (Apocynaceae) in Mexico and Central America. Brittonia 50:214-232.

Morales F.J. 2005. Estudios en las Apocynaceae neotropicales IX: Mandevilla antioquiana, sp. nov. y lectotipificación de Echites comosa. Anales del Jardín Botánico de Madrid 62:65-68

Morales F.J. 2007a. Estudios en las Apocynaceae Neotropicales XXX: tres nuevas especies andinas de Mandevilla (Apocynoideae: Mesechiteae). Journal of the Botanical Research Institute of Texas 1:853-857.

Morales F.J. 2007b. Estudios en las Apocynaceae neotropicales XXXI: el complejo de Mandevilla hirsuta y cuatro nuevas especies. Journal of the Botanical Research Institute of Texas 1:859-869.

Morales F.J. 2009a. La familia Apocynaceae (Apocynoideae, Rauvolfioideae) en Guatemala. Darwiniana 47:140-184.

Morales F.J. 2009b. Mandevilla. In: Davidse G., Sousa S.M., Knapp S. y Chiang C.F. Eds. Flora Mesoamericana Vol. 4. Parte 1, pp. 681-683. Universidad Nacional Autónoma de México, Instituto de Biología, Missouri Botanical Garden, The Natural History Museum (London), México, D.F.

Morales J.F. y Fuentes A. 2004. Estudios en las Apocynaceae Neotropicales VIII: nuevas especies de Mandevilla (Apocynoideae, Mesechiteae) para Perú y Bolivia, con notas sobre la morfología floral en corolas infundibuliformes. Candollea 59:167-174.

Müller J. 1860. Species novae americanae ex Ordine Apocyncarum et observationes quaedam in species generis Echitis Auctorum earumque distributio in genera emenda et nova. Linnaea 30:387-454. 
Nelson S.C. 1997. Material tipo de la colección de Sessé y Mociño en el Real Jardín Botánico de Madrid. Anales del Jardín Botánico de Madrid 55:375-418.

Pichon M. 1948. Classification des Apocynacées: X. Genre Mandevilla. Bulletin du Muséum National d'Histoire Naturelle. Série 2. 20:211-216.

Pichon, M. 1950. Classification des Apocynacées: XXV, Échitöidées. Mémoires du Muséum National d'Histoire Naturelle. Série. B, Botanique 1:1-143.

Rzedowski J. y Calderón de Rzedowski G. 1998. Apocynaceae. Flora del Bají y de Regiones Adyacentes. Fascículo 70. Instituto de Ecología, A.C., Centro Regional del Bajío. Comisión Nacional para el Conocimiento y Uso de la Biodiversidad, Pátzcuaro.

Sennblad B. y Bremer B. 1996. The familial and subfamilial relationships of Apocynaceae and Asclepiadaceae evaluated with $r b c \mathrm{~L}$ data. Plant Systematic and Evolution 202:153-175.

Simões A.O., Kinoshita L.S. y Endress M.E. 2007. New combinations in Mandevilla Lindley (Apocynaceae). Novon 17:87-90.

Simões A.O., Endress M.E., van der Niet T., Kinoshita L.S. y Conti E. 2004. Tribal and intergeneric relationships of Mesechiteae (Apocynoideae, Apocynaceae): evidence from three noncoding plastid DNA regions and morphology. American Journal of Botany 91:1409-1418.

Simões A.O., Endress M.E., van der Niet T., Kinoshita L.S. y Conti E. 2006. Is Mandevilla (Apocynaceae, Mesechiteae) monophyletic? Evidence from five plastid DNA loci and morphology. Annals of the Missouri Botanical Garden 93:565-591.

Recibido: 15 de enero de 2013

Aceptado: 5 de mayo de 2013
Watson S. 1887. XXI. Contributions to American botany. Proceedings of the American Academy of Arts and Science 22:396-481.

Williams J.K. 1996. The Mexican genera of the Apocynaceae (sensu A. DC.), with key and additional taxonomic notes. Sida 17:197-213.

Williams J.K. 1998a. A new species of Mandevilla (Apocynaceae) from Jalisco. Sida 18:231-235

Williams J.K. 1998b. A new combination in Mexican Mandevilla (Apocynaceae). Sida 18:237-239.

Williams J.K. 1999. A phylogentic and taxonomic study of the Apocynaceae subfamily Apocynoideae of Mexico with a synopsis of subfamily Plumerioideae. Doctor of Phylosophy Dissertation. The University of Texas, Austin, $546 \mathrm{pp}$.

Williams J.K. 2003. A new combination in Mexican Mandevilla (Apocynaceae subfamily Apocynoideae) II. Lundellia 6:144-147.

Williams J.K. 2004. A new combination in Mexican Mandevilla (Apocynaceae subfamily Apocynoideae) III. Phytologia 86:178-183.

Woodson R.E.Jr. 1932. New or otherwise noteworty Apocynaceae of tropical America II. Annals of the Missouri Botanical Garden 19:45-76.

Woodson R.E.Jr. 1933. Studies in Apocynaceae IV. The American genera of Echitoidea. Annals of the Missouri Botanical Garden 20:605-790.

Woodson R.E. 1938. North American flora (Apocynaceae). Publications of the New York Botanical Garden 29:103-192. 